Synthesis of Spiro-lactams and Polysubstituted Pyrroles via Ceric Ammonium Nitrate-Mediated Oxidative Cyclization of

\title{
$N$-Furan-2-ylmethyl- $\beta$-Enaminones
}

\author{
Hui Peng, ${ }^{\dagger}$ Jiuyi Li, ${ }^{\dagger}$ Furong Wang, ${ }^{\dagger}$ Bo Liu ${ }^{\ddagger}$ and Biaolin Yin* ${ }^{\dagger}$ \\ ${ }^{\dagger}$ School of Chemistry and Chemical Engineering, South China University of Technology, Guangzhou, P.R. China, \\ 510640 \\ ${ }^{\ddagger}$ Guangdong Provincial Academy of Chinese Medical Sciences, Guangzhou, P.R. China, 510006 \\ blyin@scut.edu.cn
}

\section{Content}

Page

Spectra of 7

Spectra of 8

$22-35$

CIF information of $\mathbf{7 c}$

36

HSQC of $7 \mathbf{a}, 7 \mathbf{b}, \mathbf{7 e}, 7 \mathbf{r}$

$37-38$ 


\section{Spectra of 7}
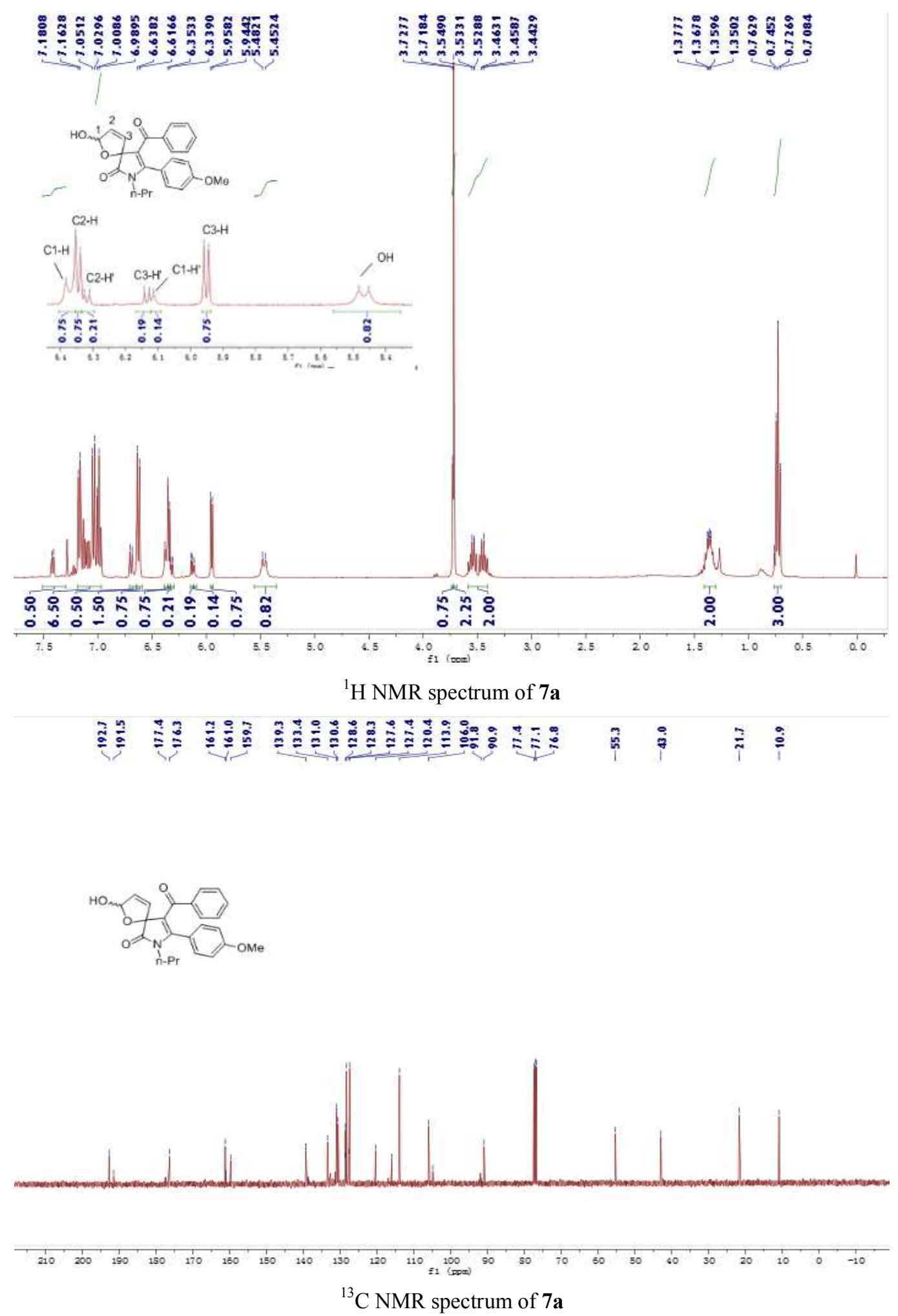


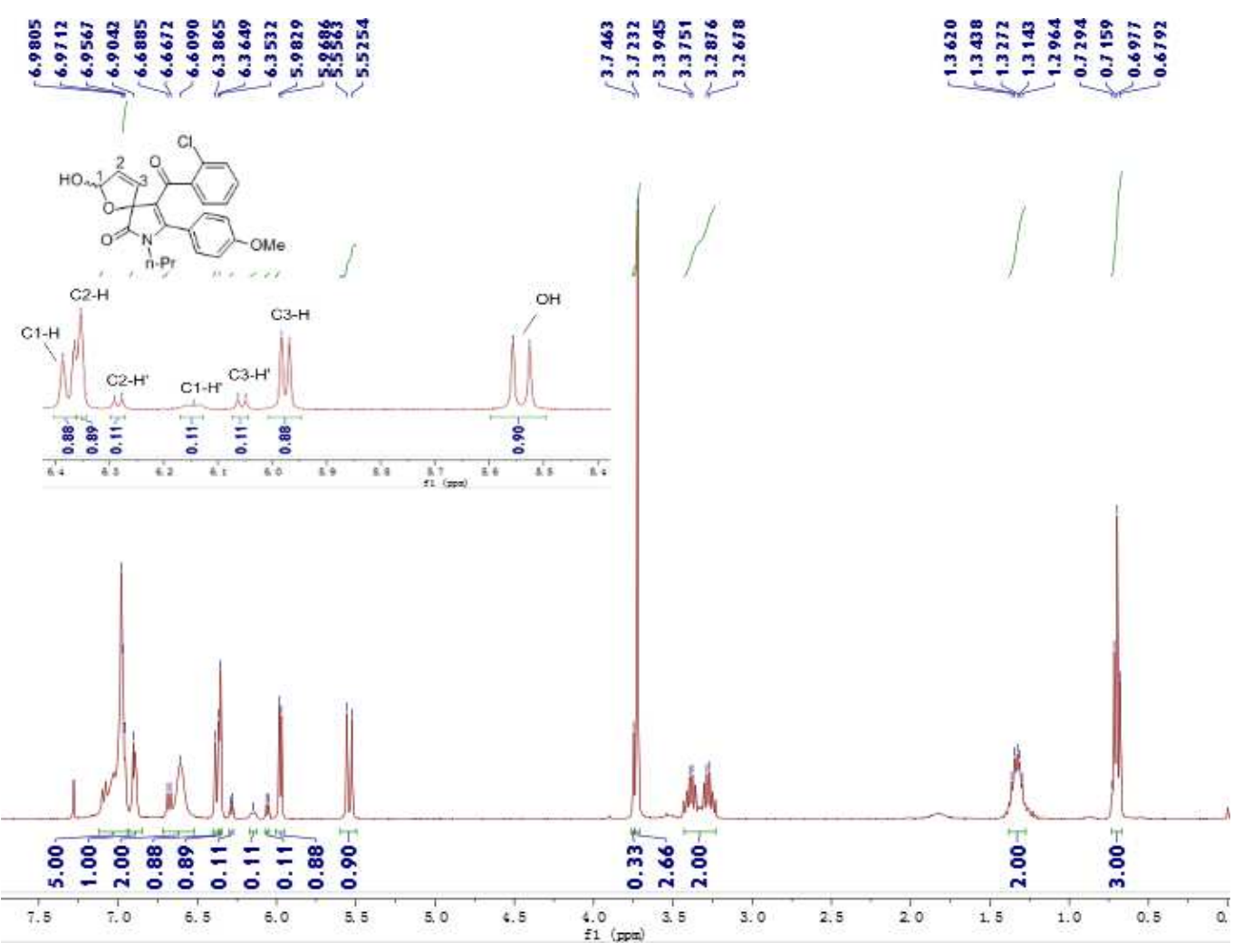

${ }^{1} \mathrm{H}$ NMR spectrum of $\mathbf{7 b}$

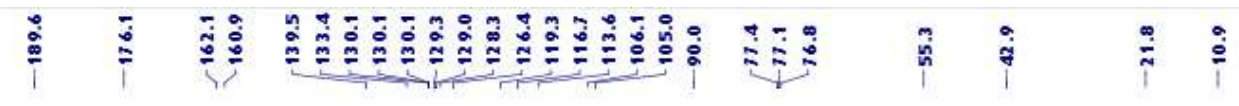
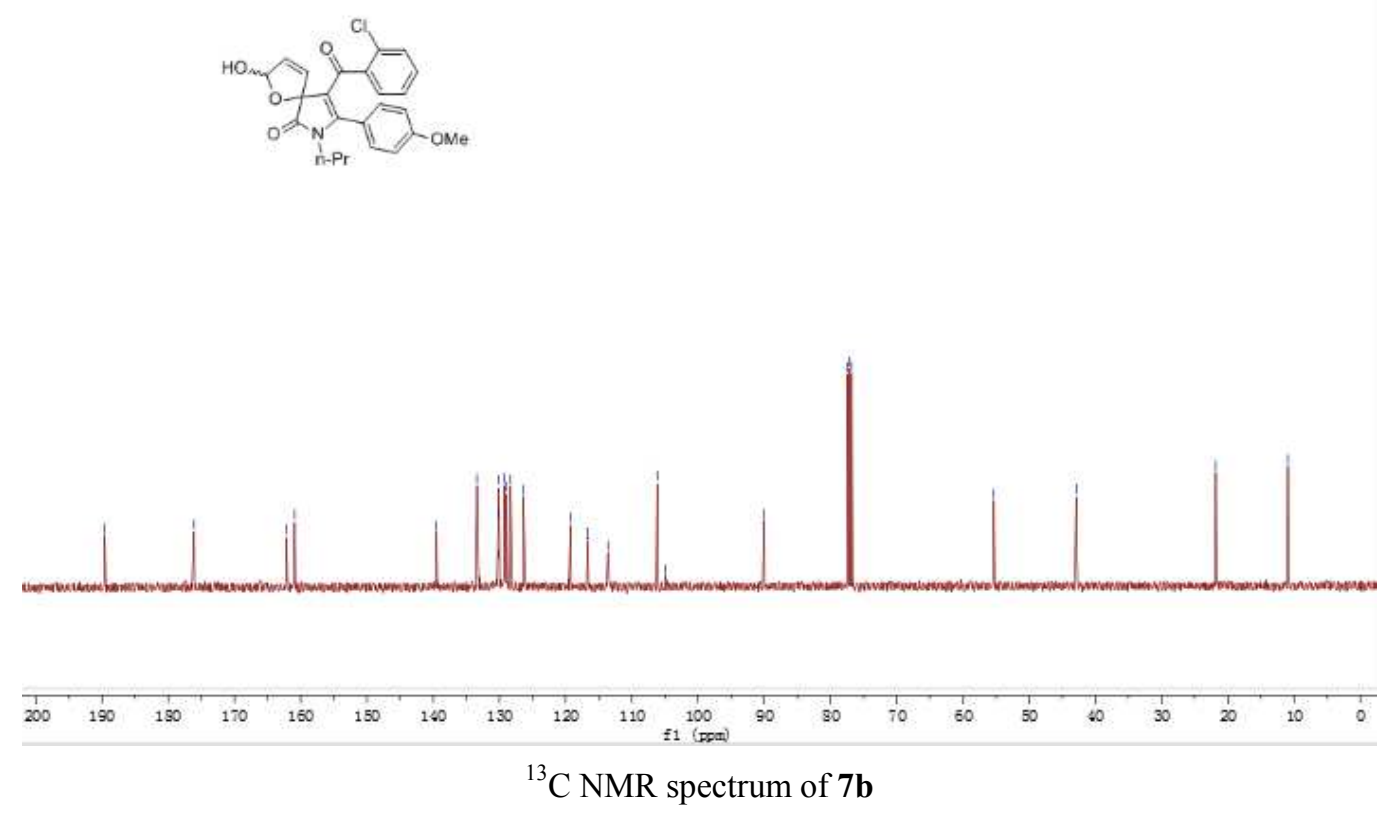

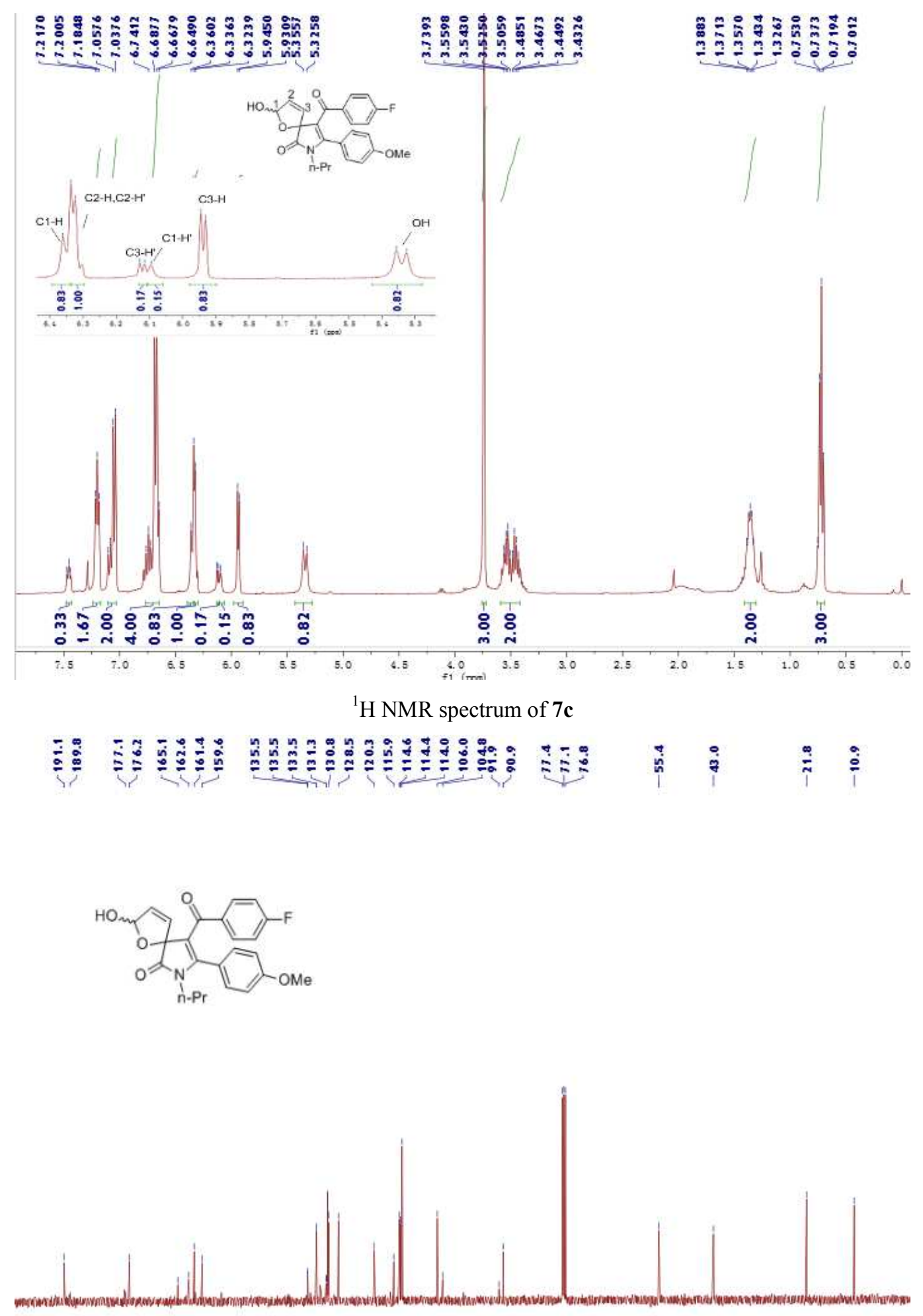

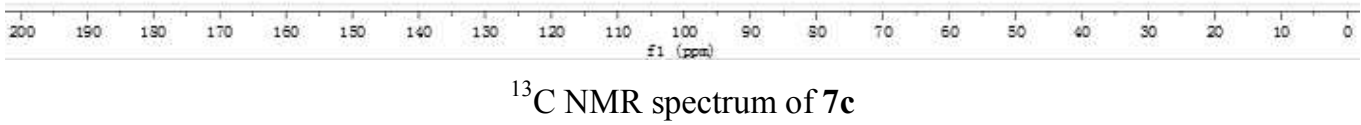




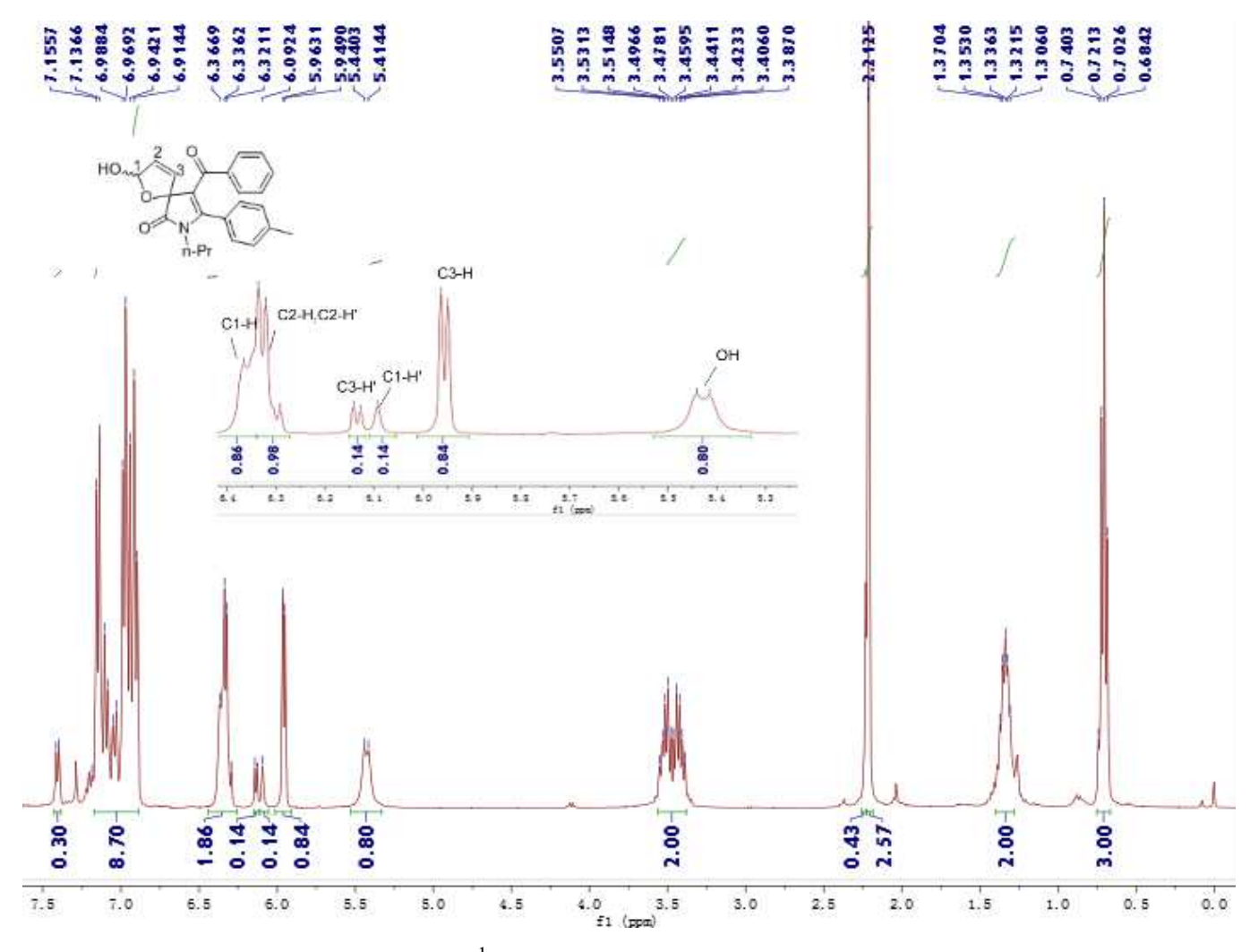

${ }^{1} \mathrm{H}$ NMR spectrum of $7 \mathbf{d}$
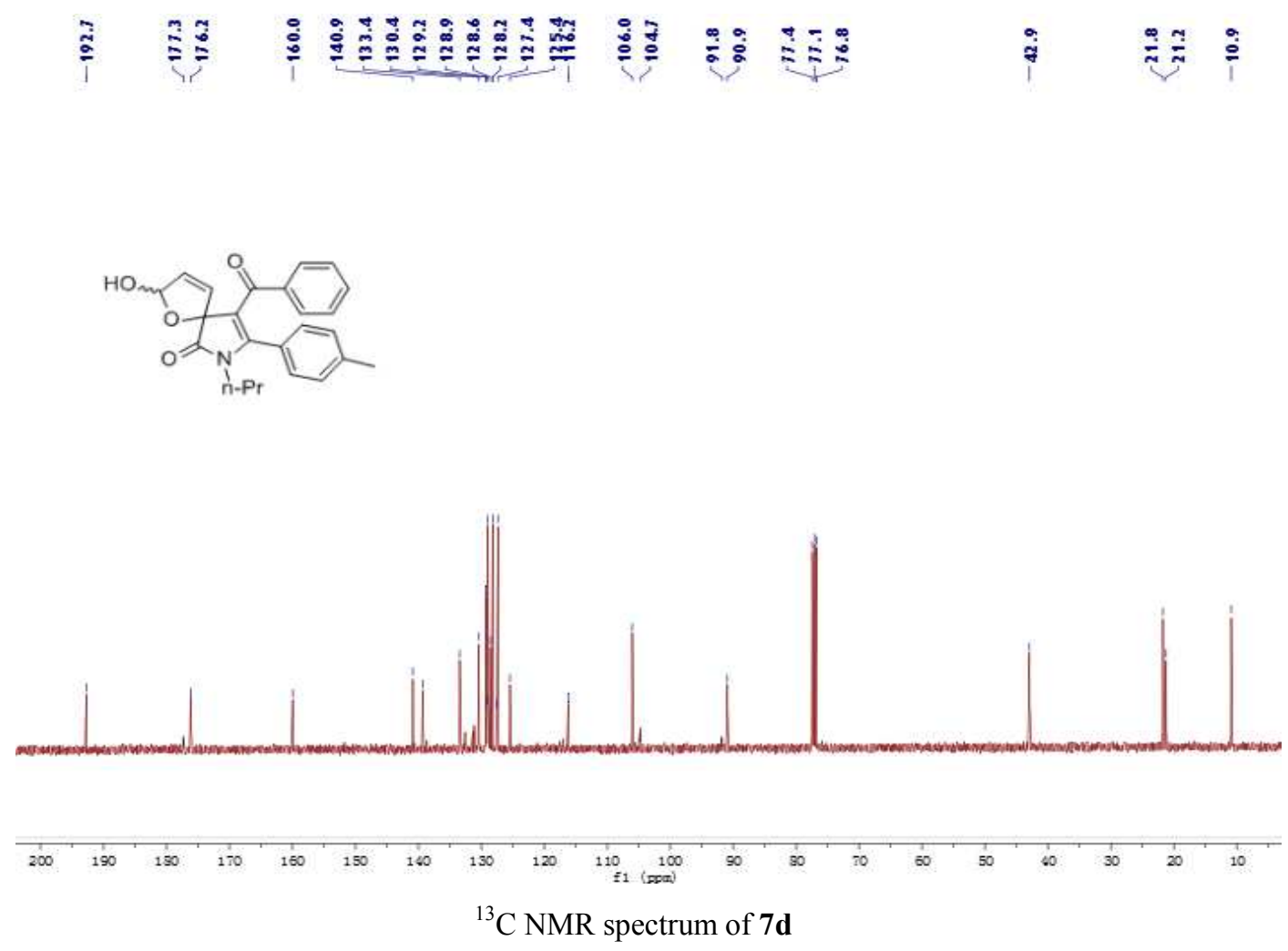


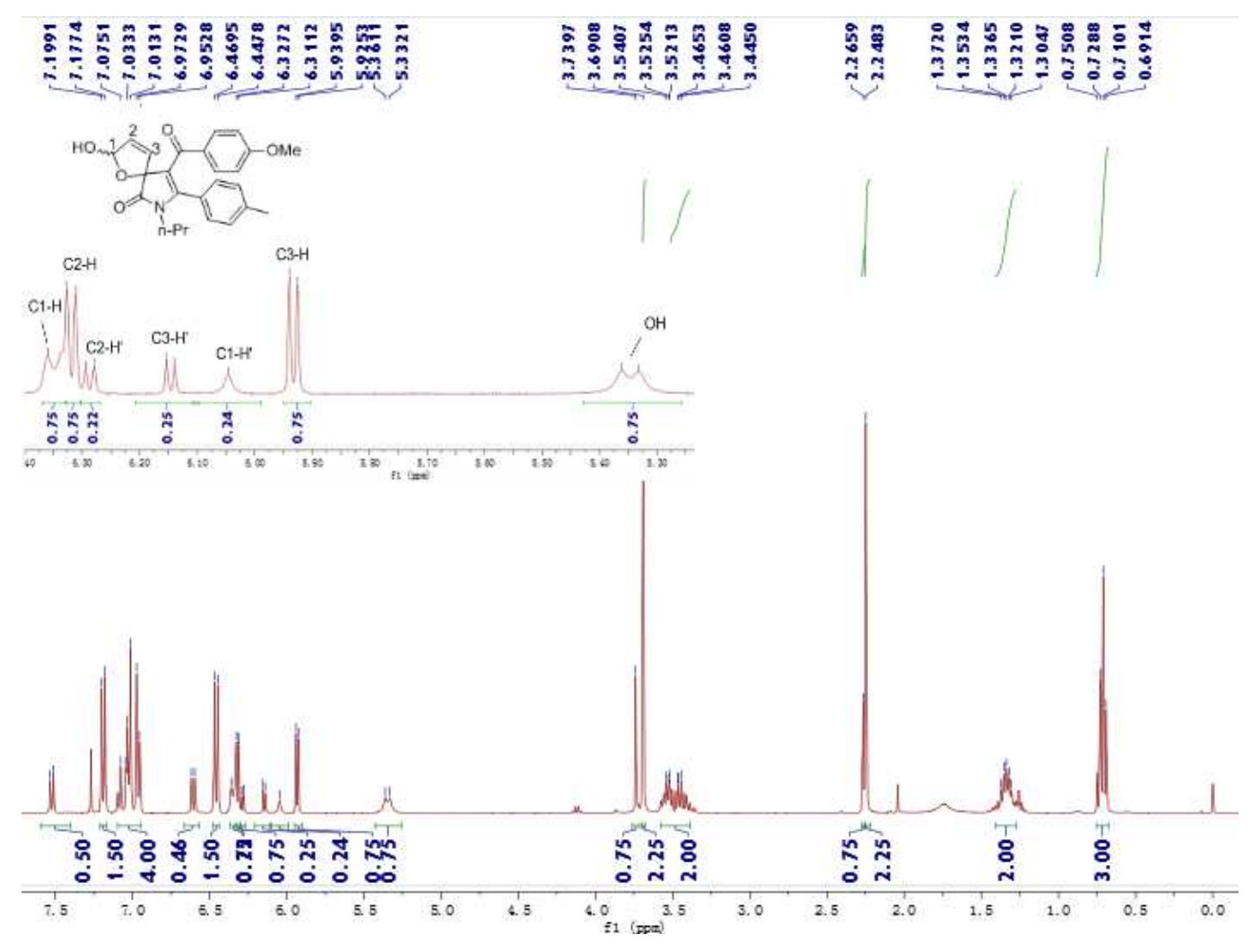

${ }^{1} \mathrm{H}$ NMR spectrum of $\mathbf{7 e}$

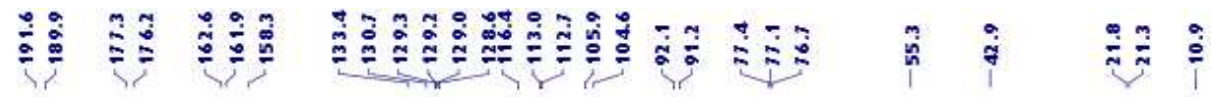
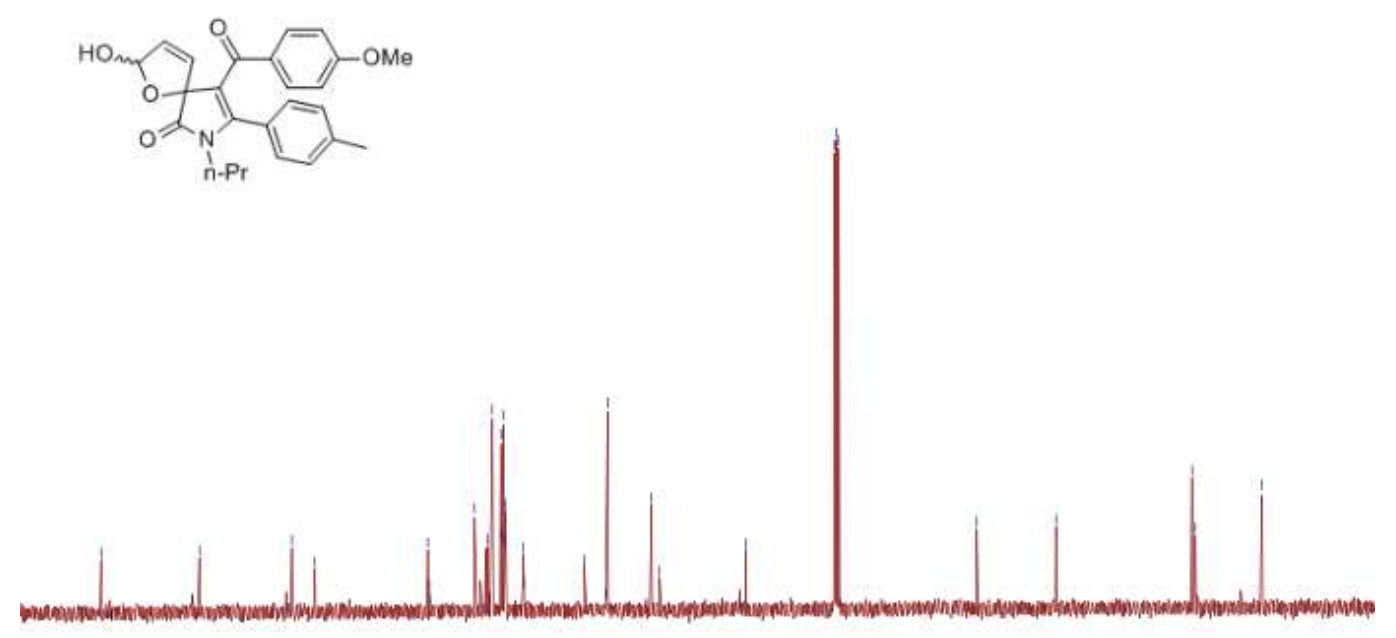

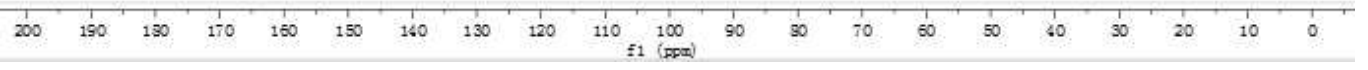

${ }^{13} \mathrm{C}$ NMR spectrum of $7 \mathbf{e}$ 

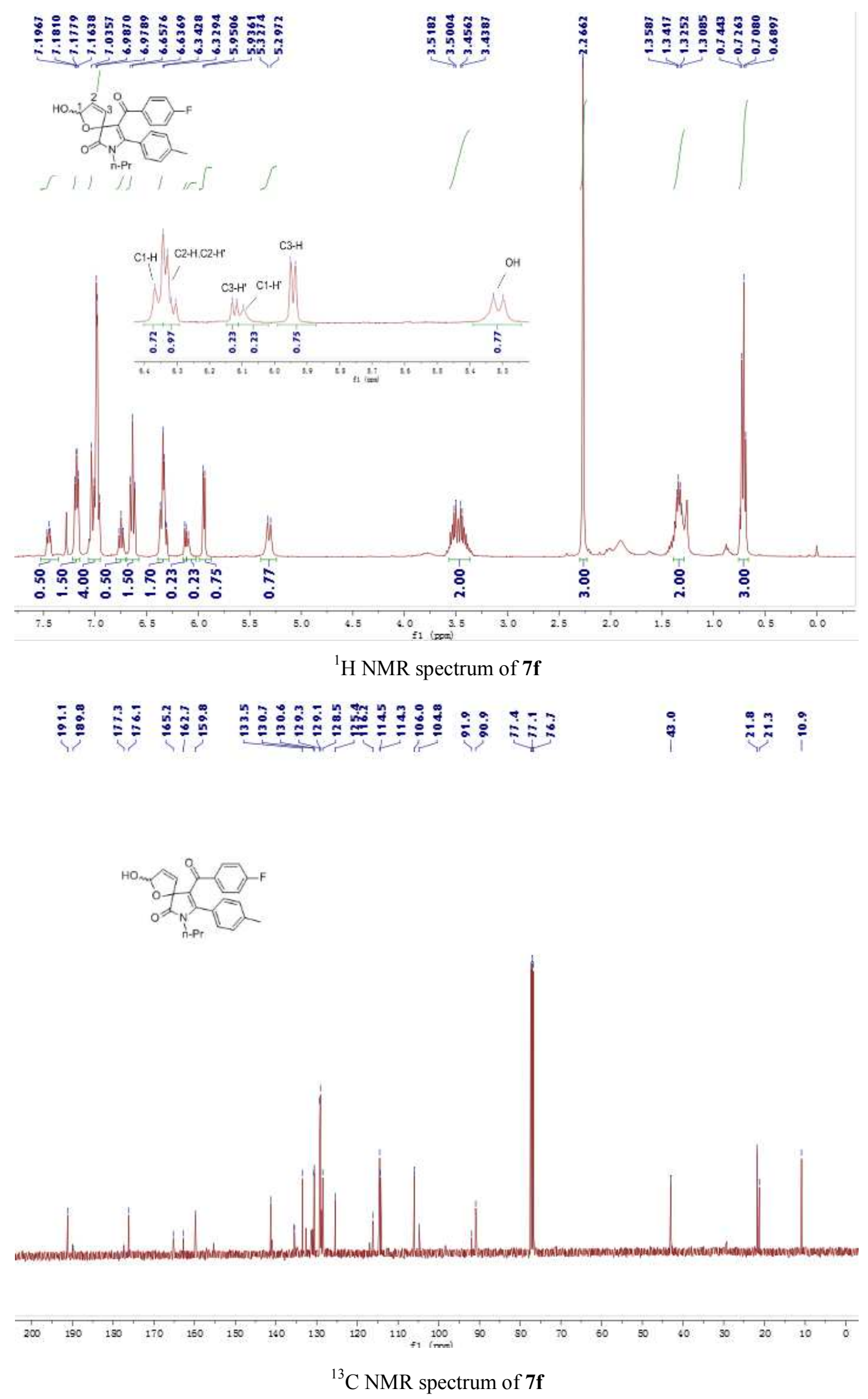


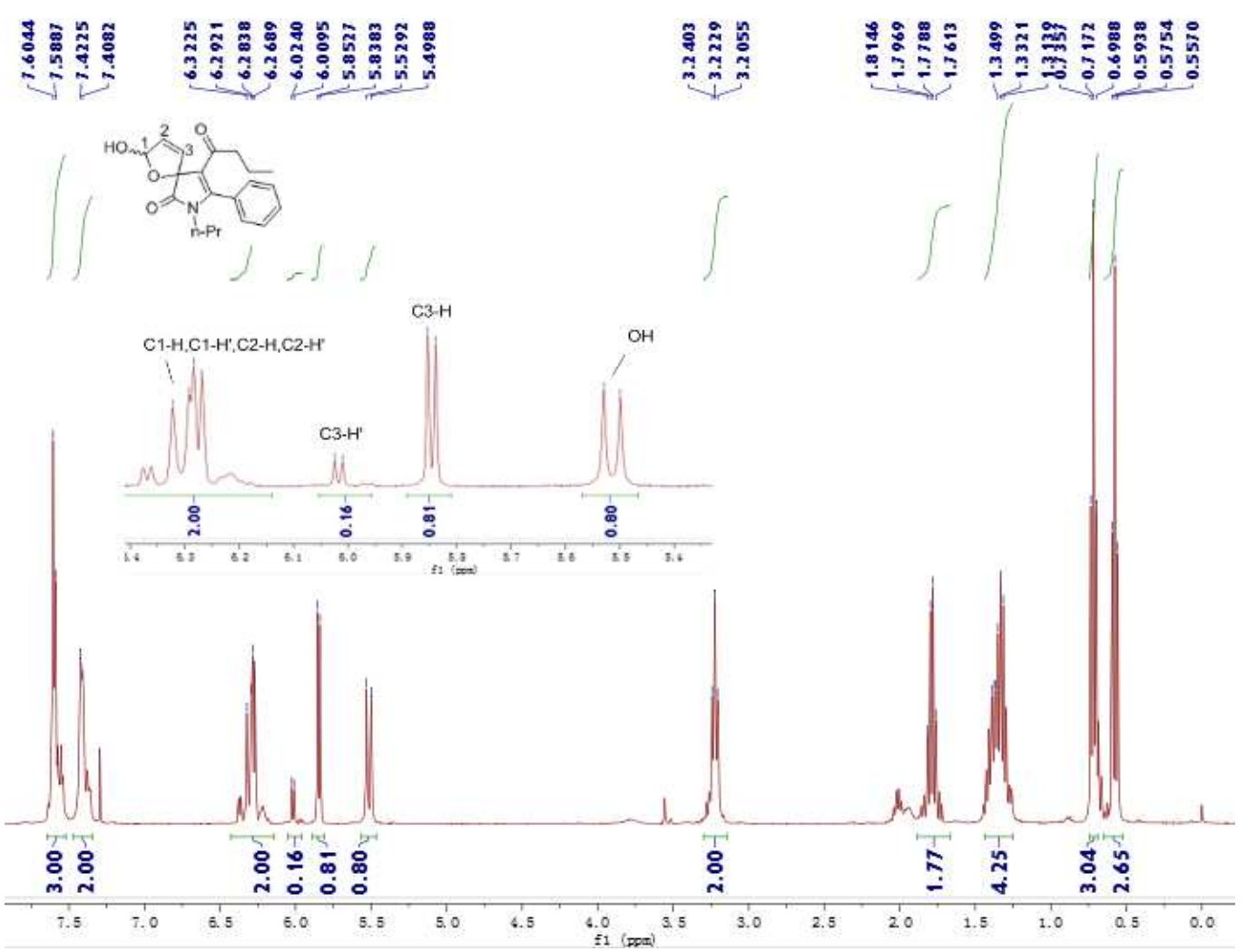

${ }^{1} \mathrm{H}$ NMR spectrum of $7 \mathbf{g}$

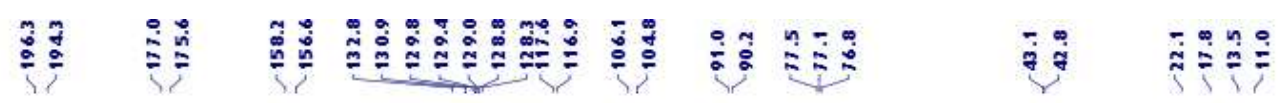
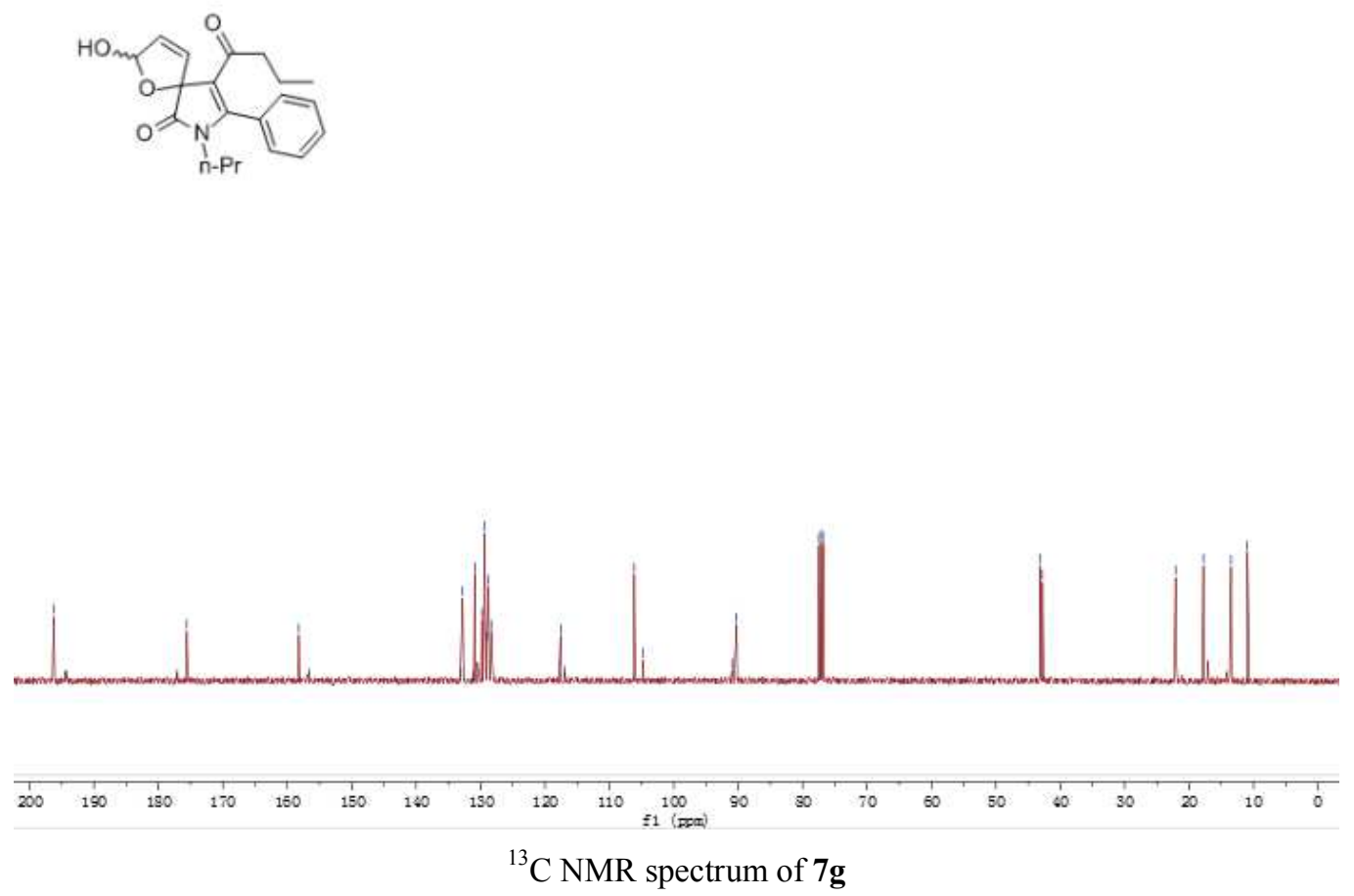

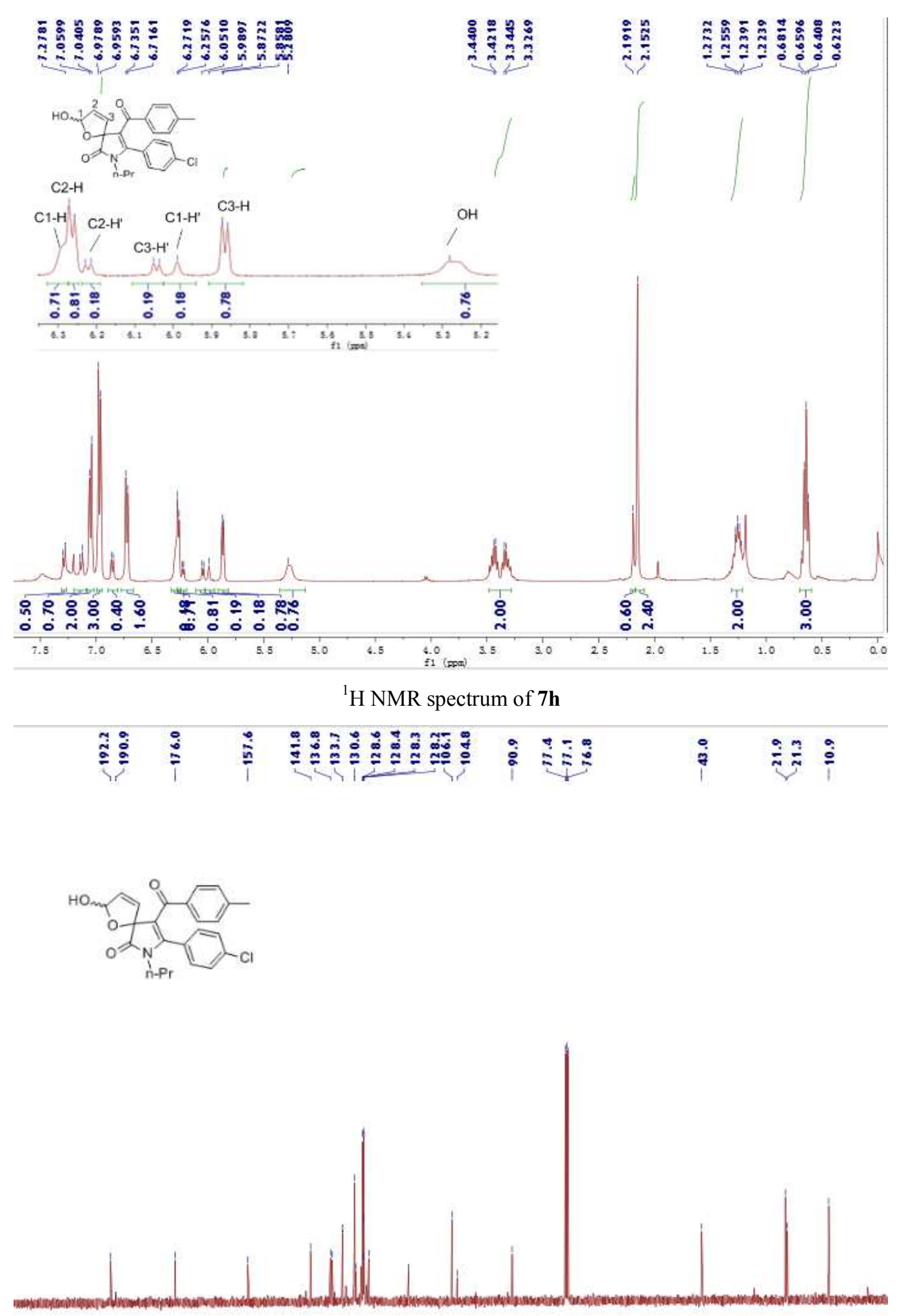

\begin{tabular}{|c|c|c|c|c|c|c|c|c|c|c|c|c|c|c|c|c|c|c|c|c|}
\hline 210 & 200 & 190 & 190 & 170 & 160 & 150 & 160 & 130 & 120 & $110 \quad 100$ & 90 & so & 70 & 60 & so & 10 & 30 & 20 & 10 & 1 \\
\hline
\end{tabular}



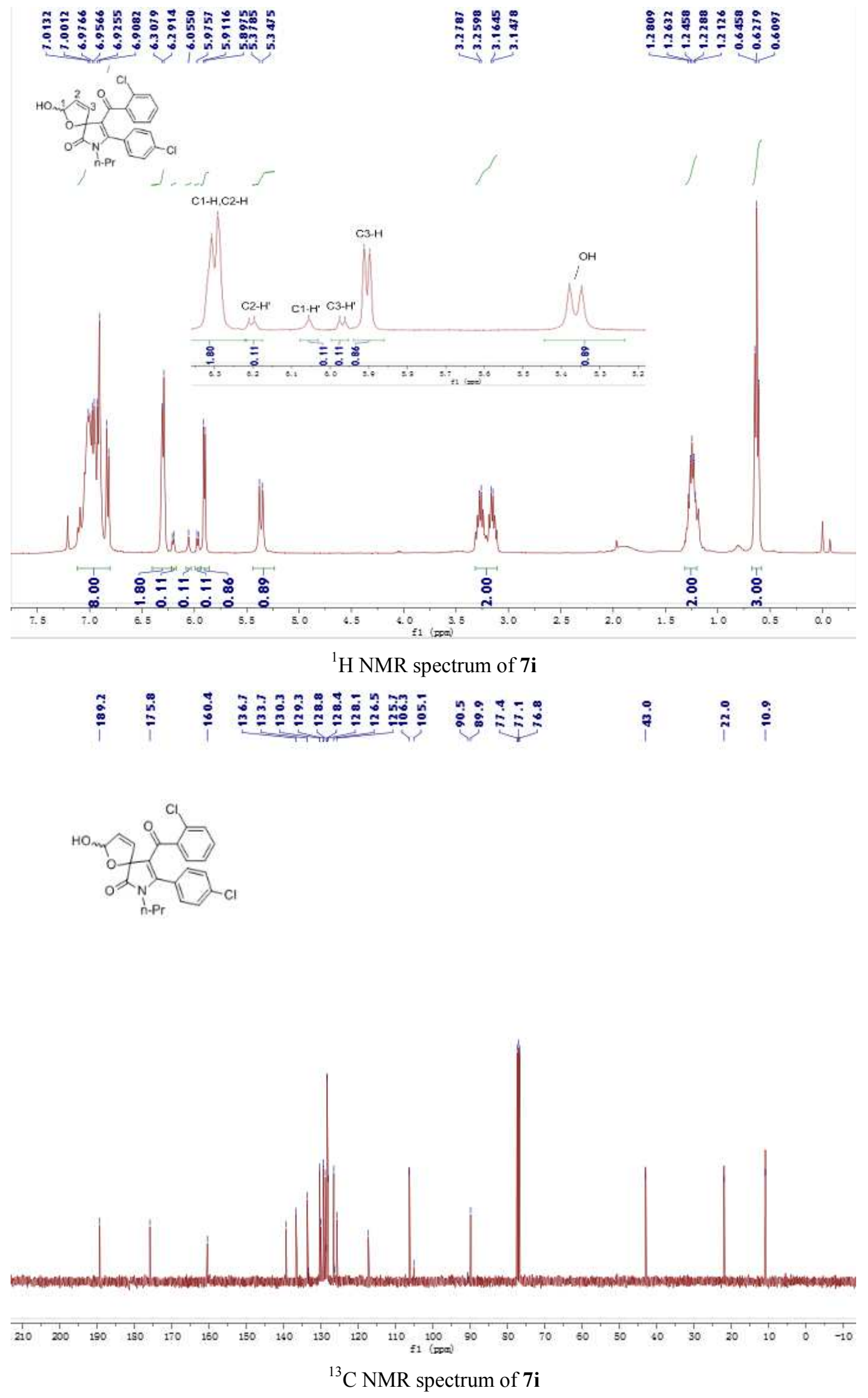

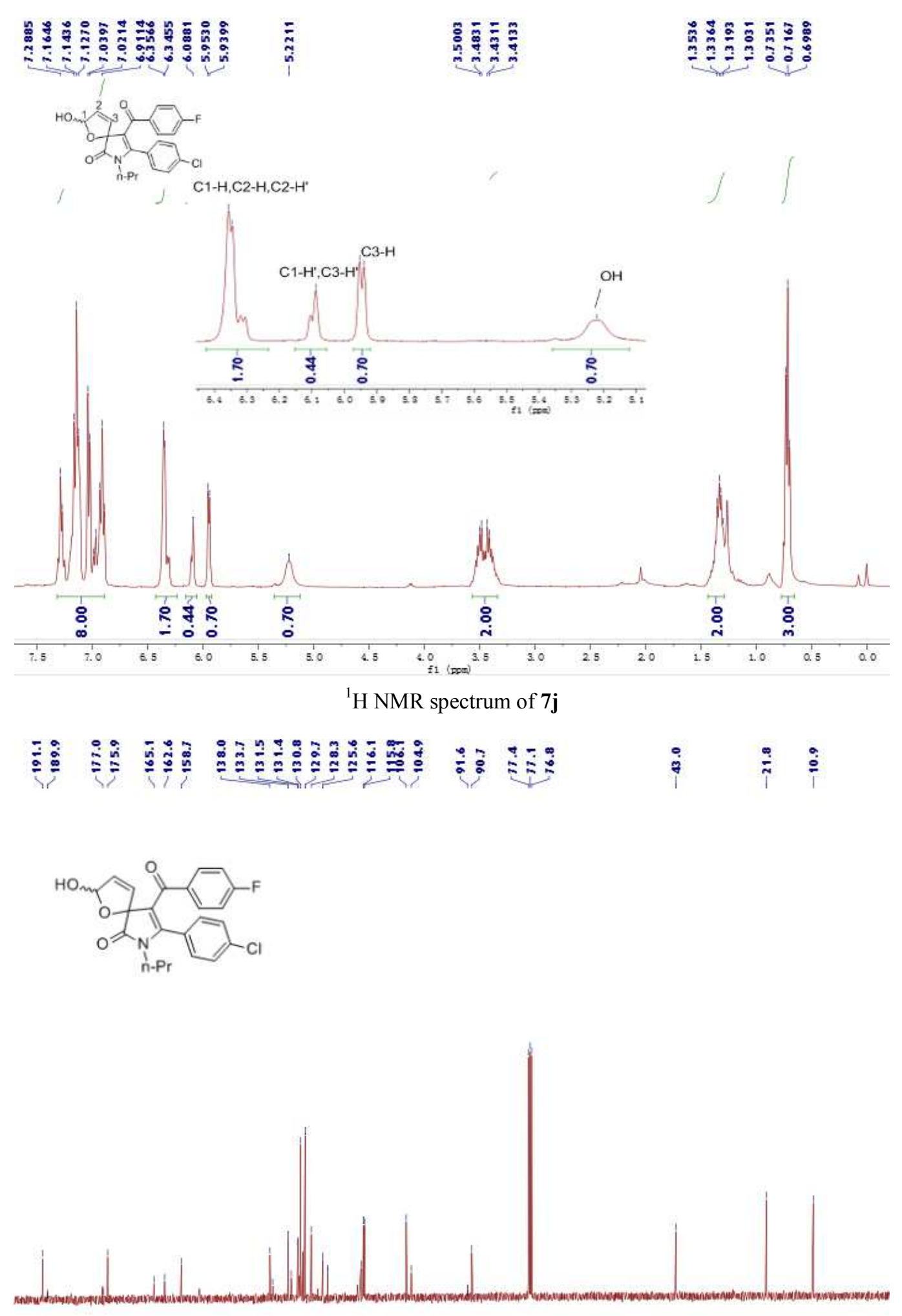

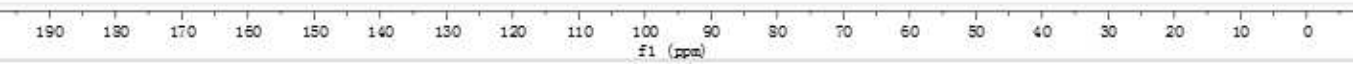

${ }^{13} \mathrm{C}$ NMR spectrum of $\mathbf{7 j}$ 

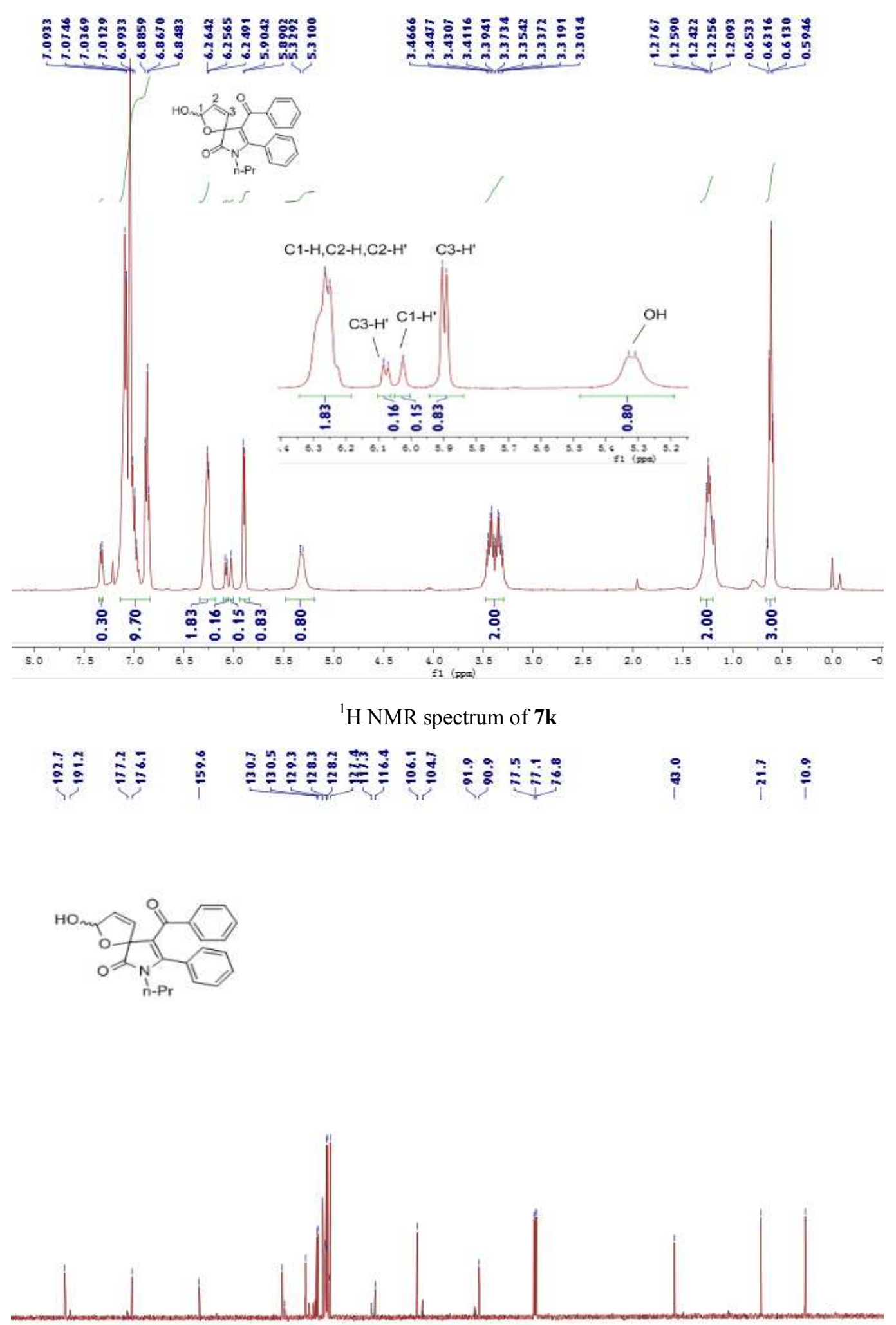

${ }^{13} \mathrm{C}$ NMR spectrum of $7 \mathbf{k}$ 


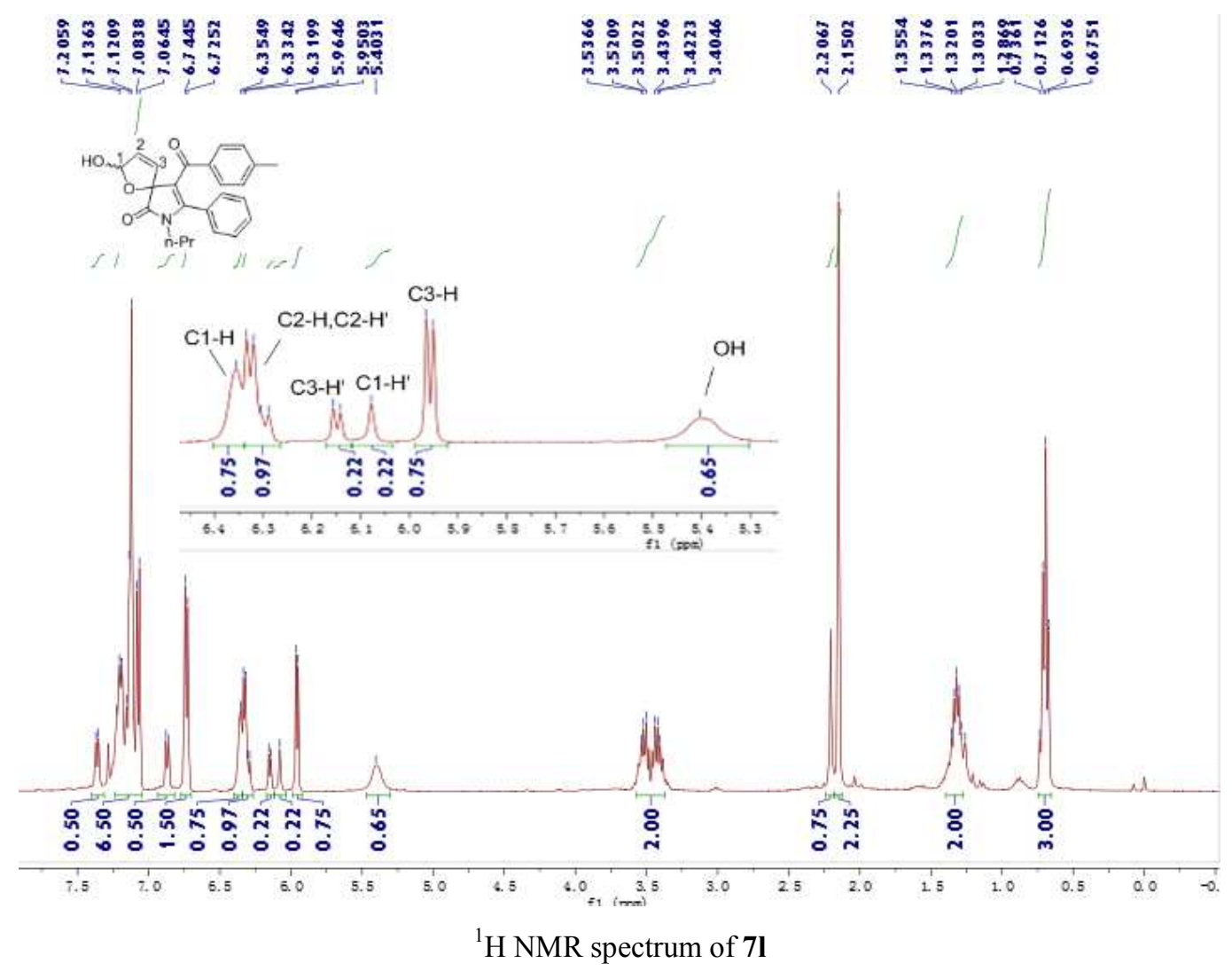

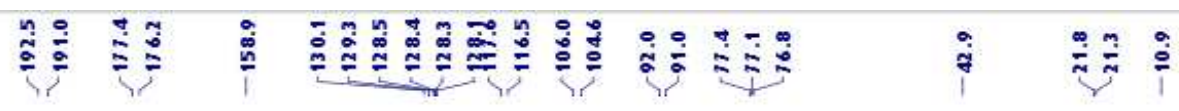
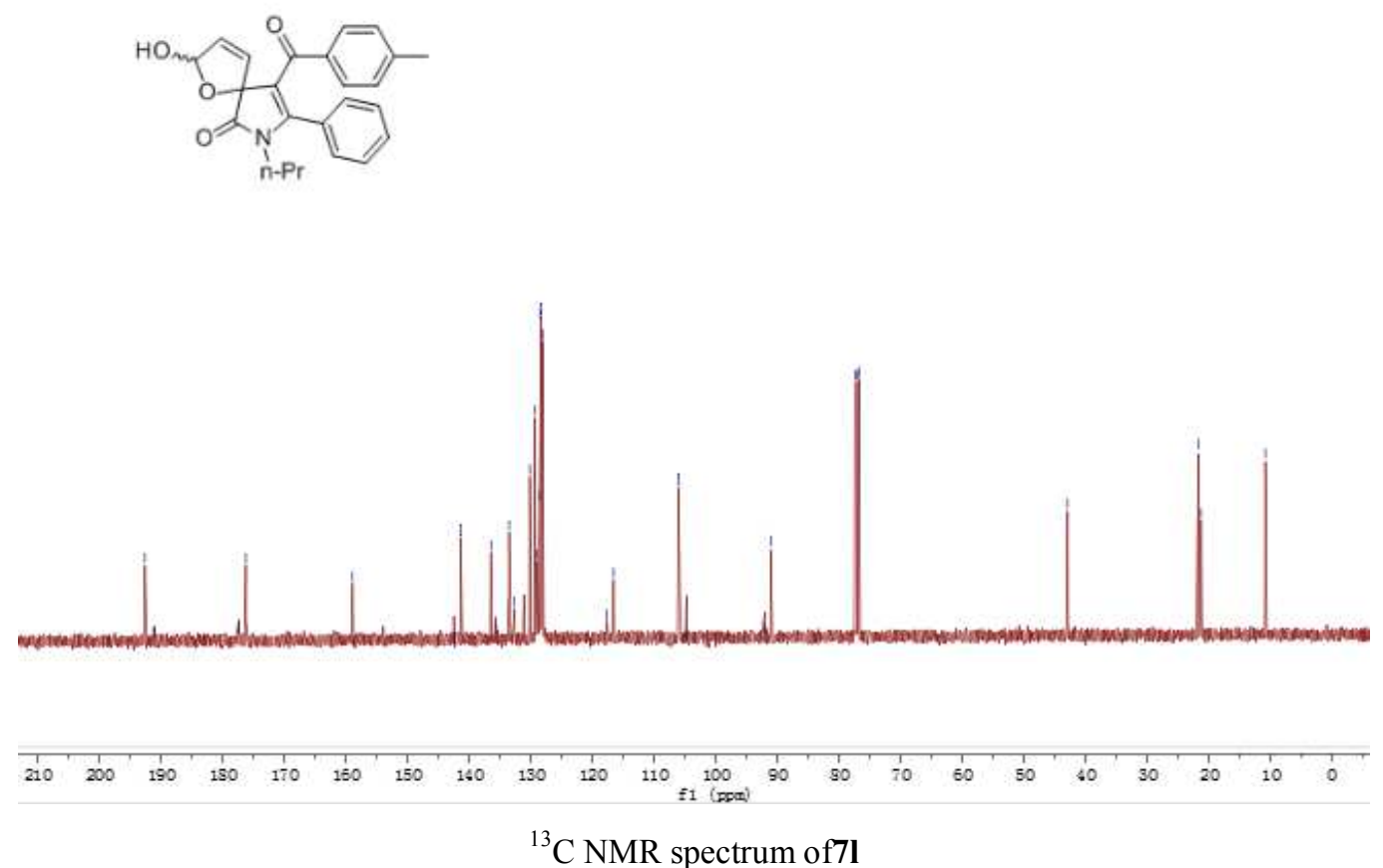


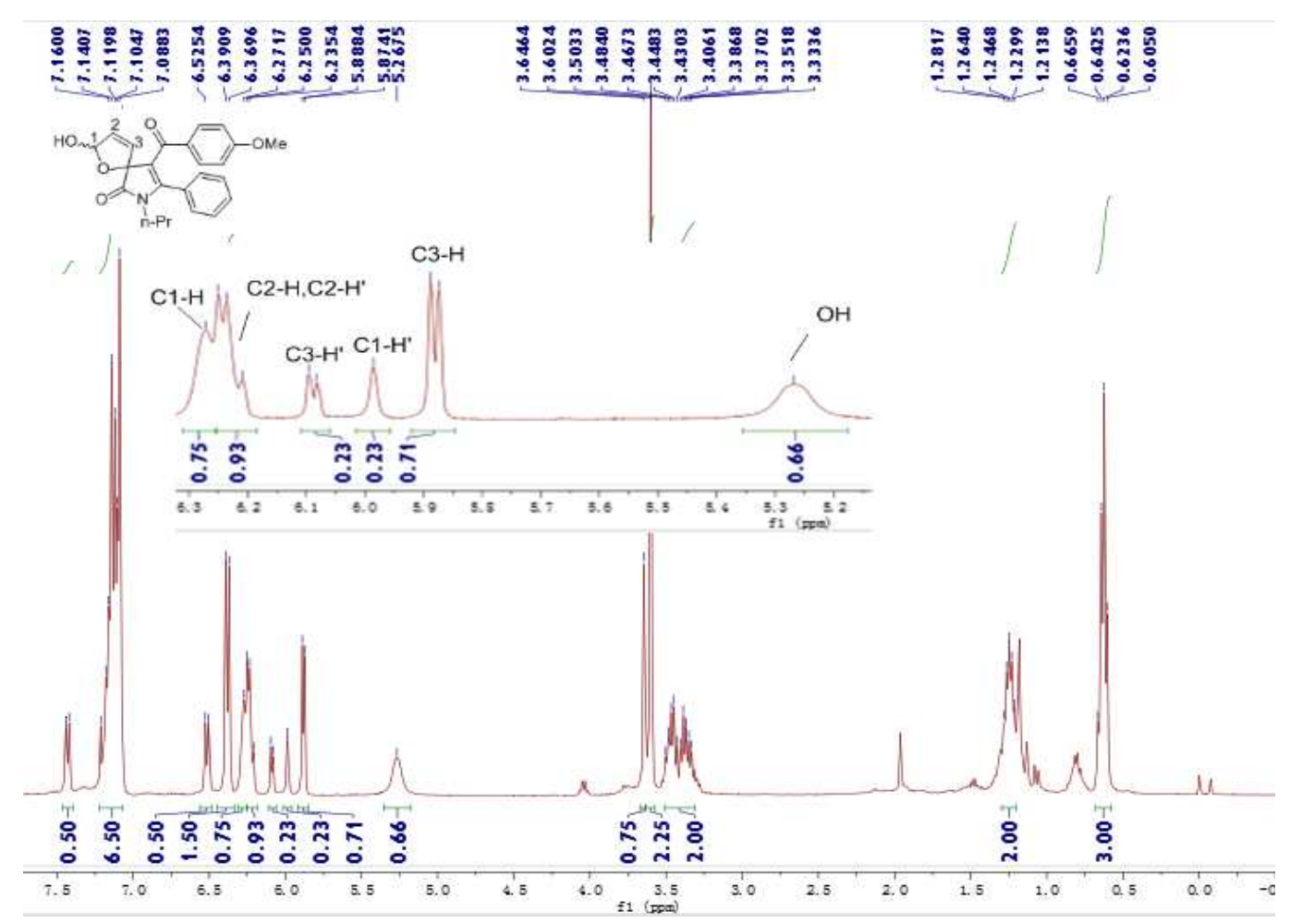

${ }^{1} \mathrm{H}$ NMR spectrum of $7 \mathbf{m}$

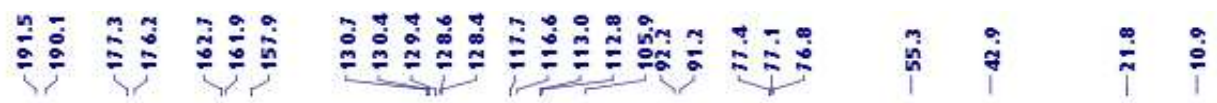
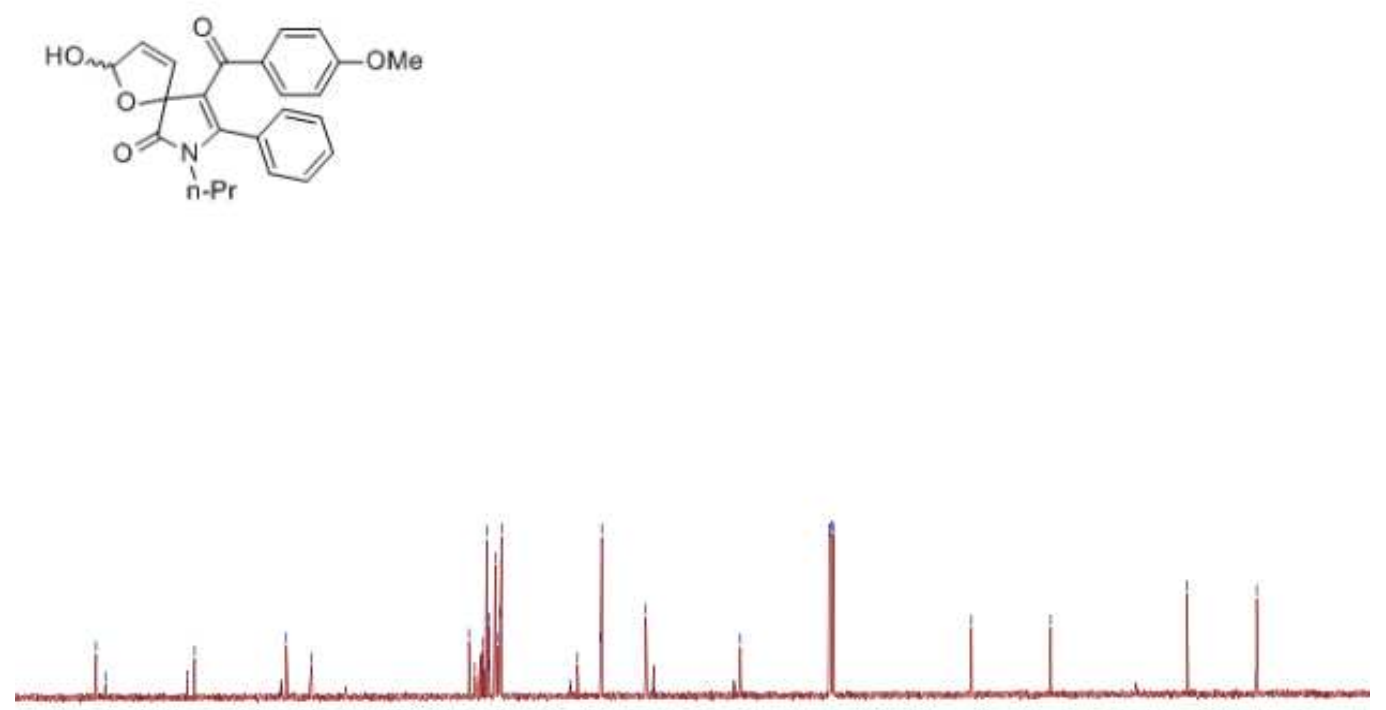

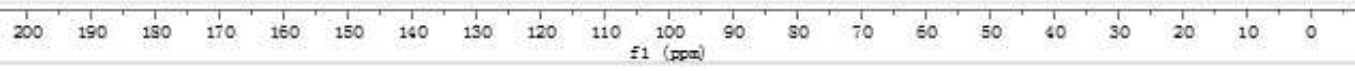

${ }^{13} \mathrm{C}$ NMR spectrum of $\mathbf{7 m}$ 


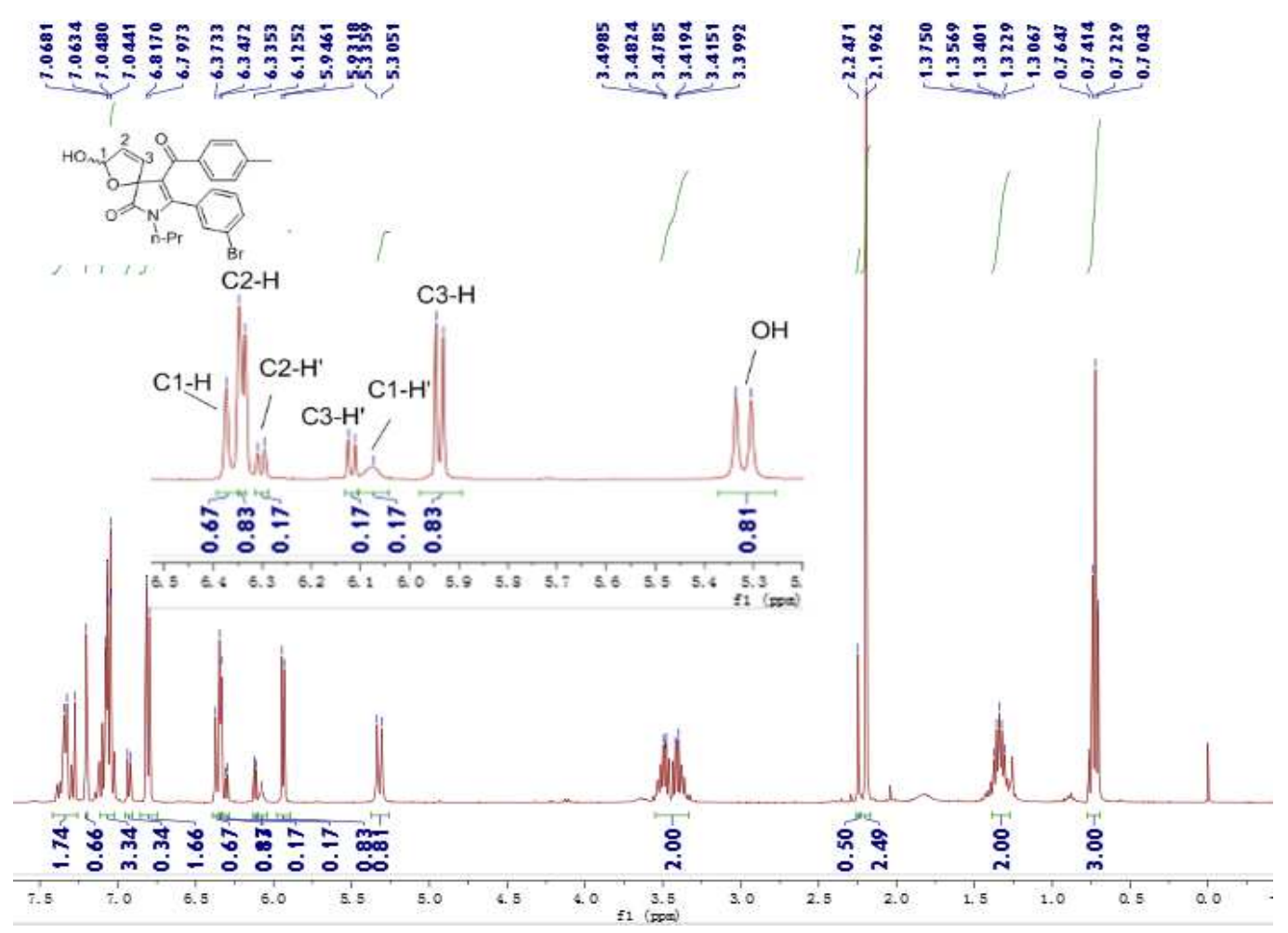

${ }^{1} \mathrm{H}$ NMR spectrum of $\mathbf{7 n}$

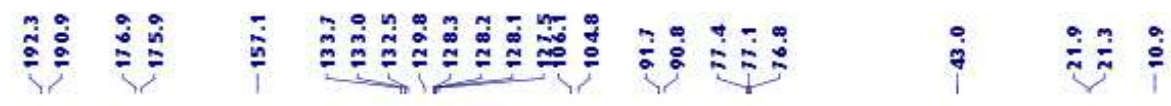
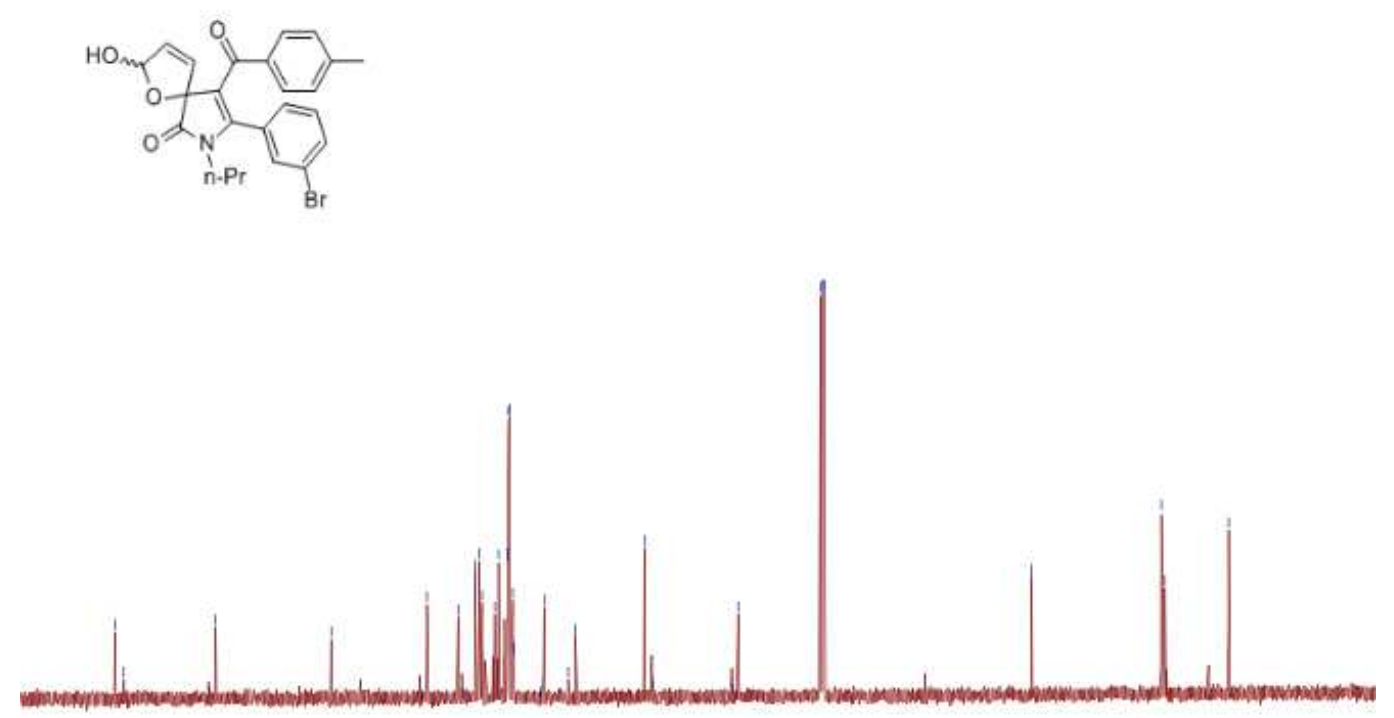

\begin{tabular}{|c|c|c|c|c|c|c|c|c|c|c|c|c|c|c|c|c|c|c|c|c|}
\hline 200 & 190 & 190 & 170 & 160 & 150 & 160 & 130 & 120 & $110 \quad 100$ & 90 & 90 & 70 & 60 & 50 & 60 & so & 20 & 10 & 0 & -10 \\
\hline
\end{tabular}



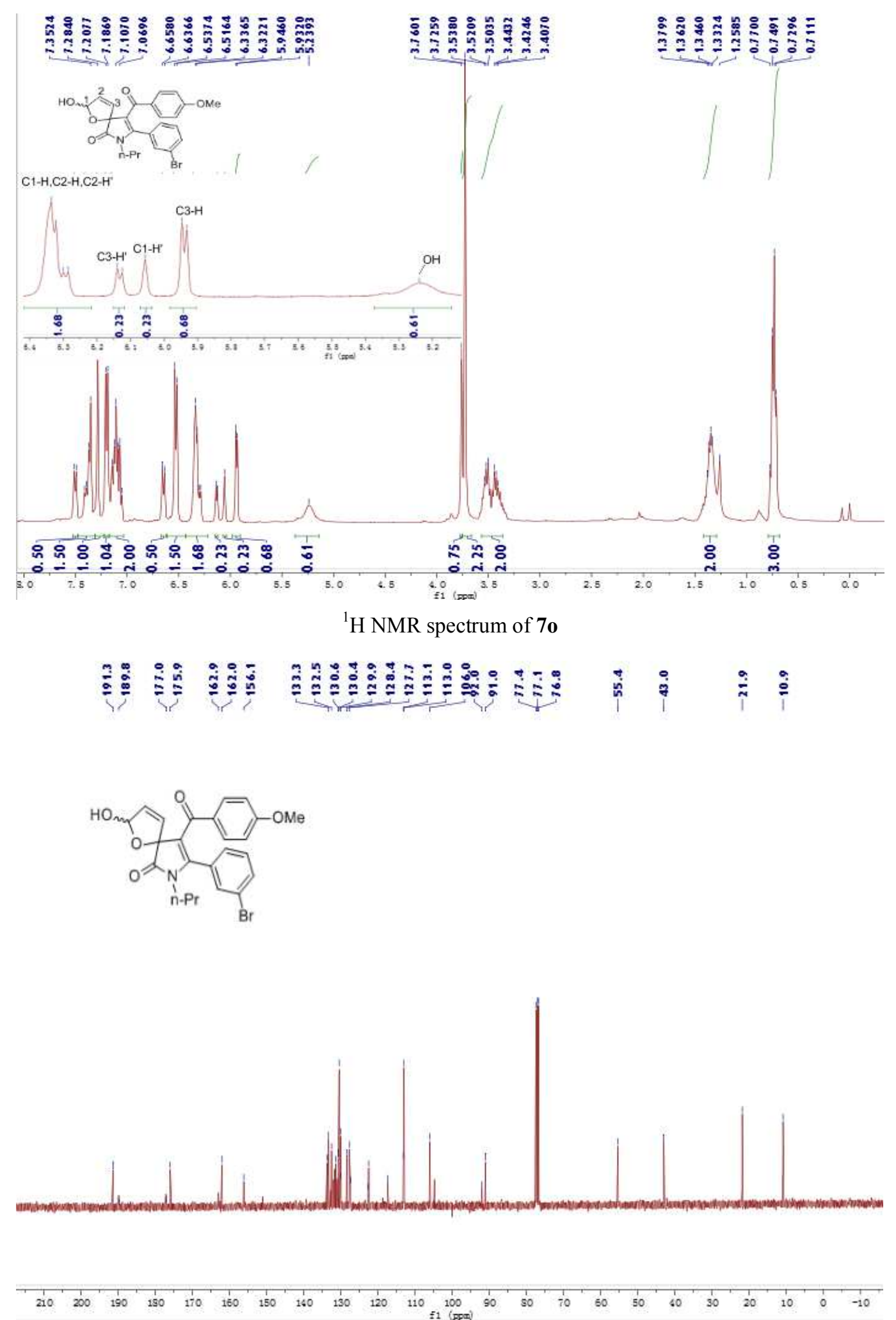

${ }^{13} \mathrm{C}$ NMR spectrum of $7 \mathbf{o}$ 

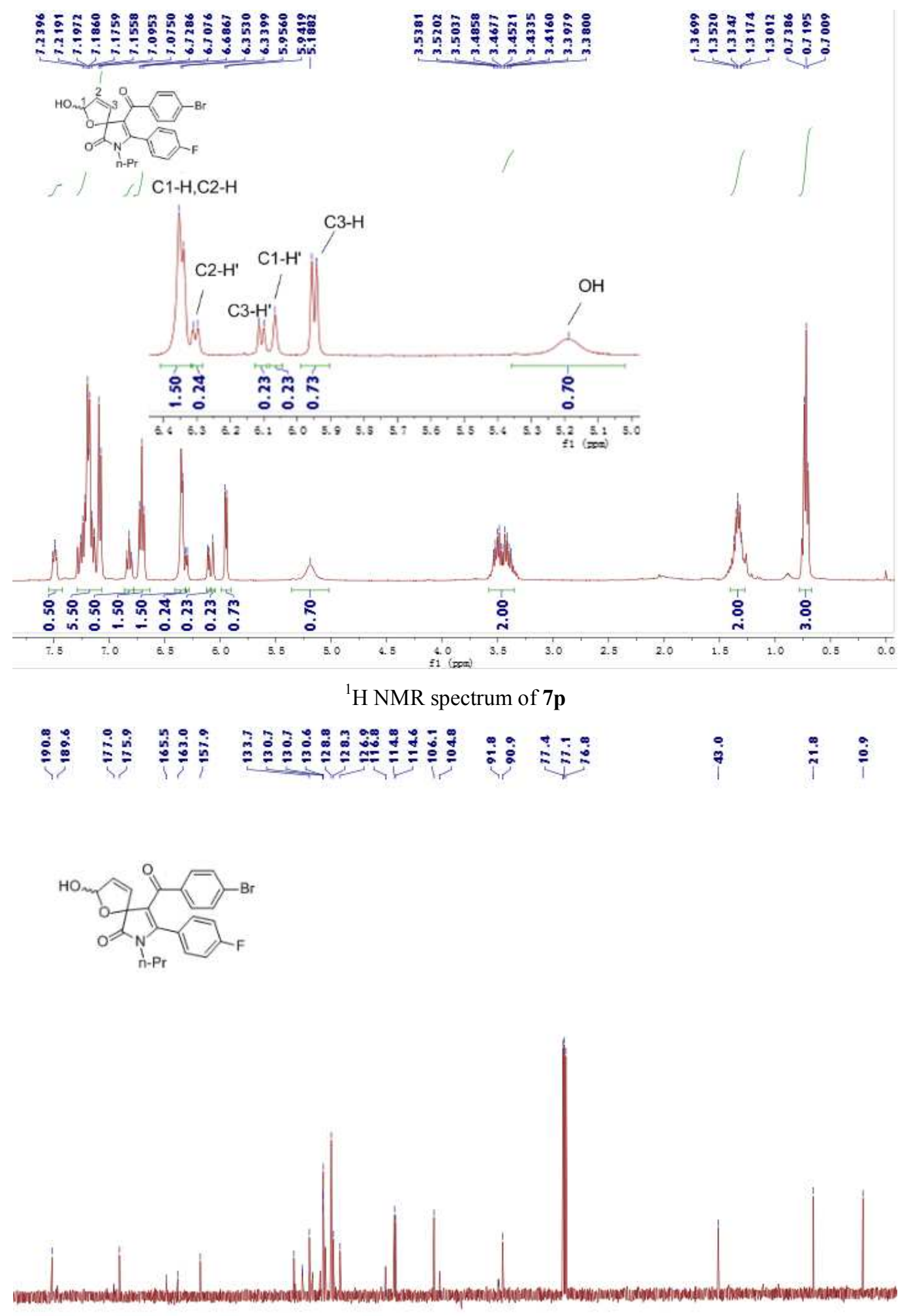

\begin{tabular}{|c|c|c|c|c|c|c|c|c|c|c|c|c|c|c|c|c|c|}
\hline 190 & 150 & 170 & 160 & 150 & 100 & 130 & 120 & $110 \quad 100$ & 90 & 30 & 70 & 60 & 50 & 40 & 30 & 20 & 10 \\
\hline
\end{tabular}




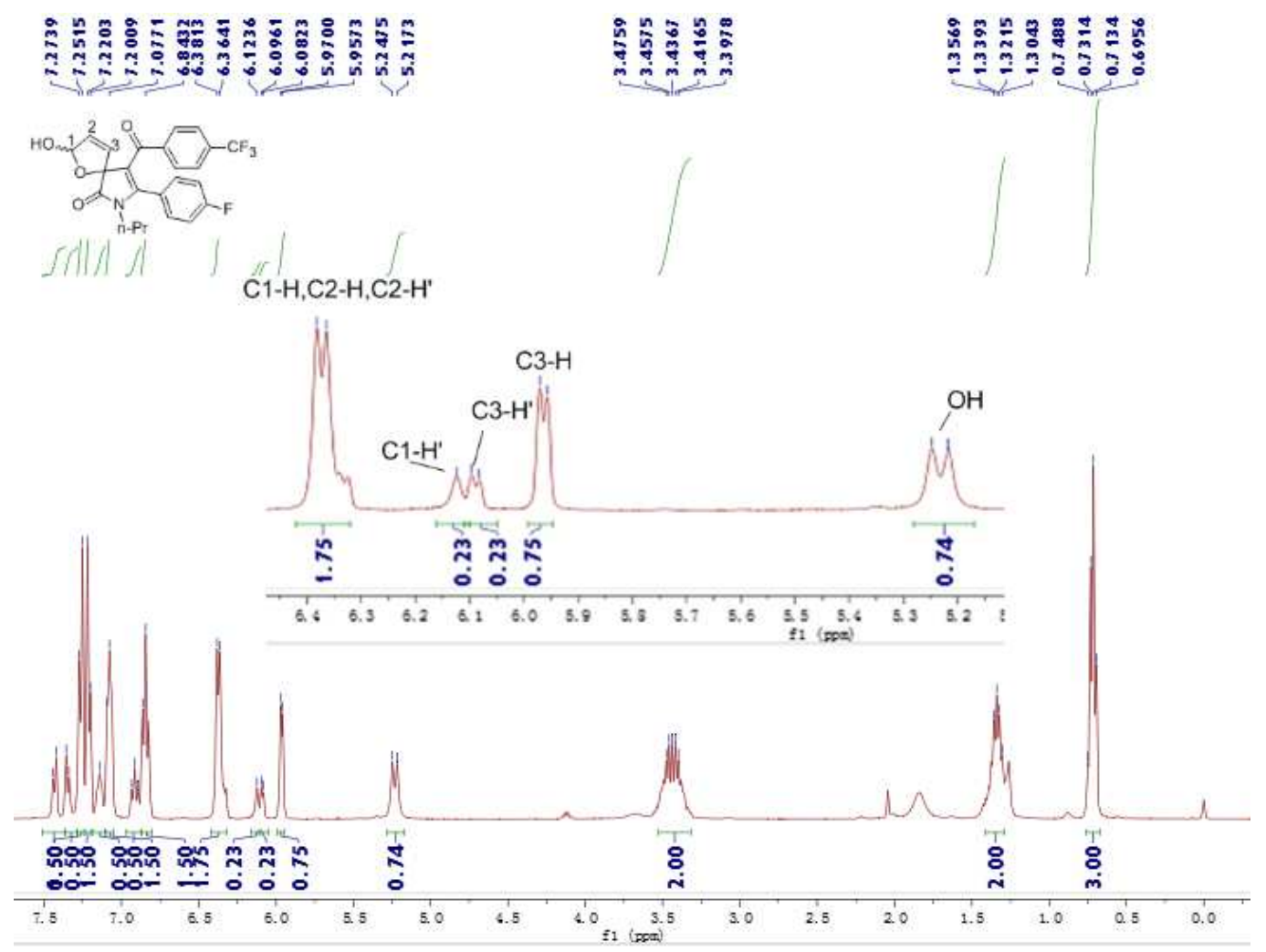

${ }^{1}$ H NMR spectrum of $\mathbf{7 q}$

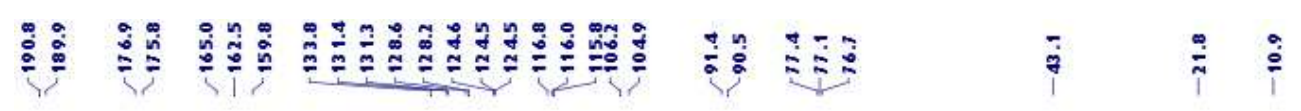
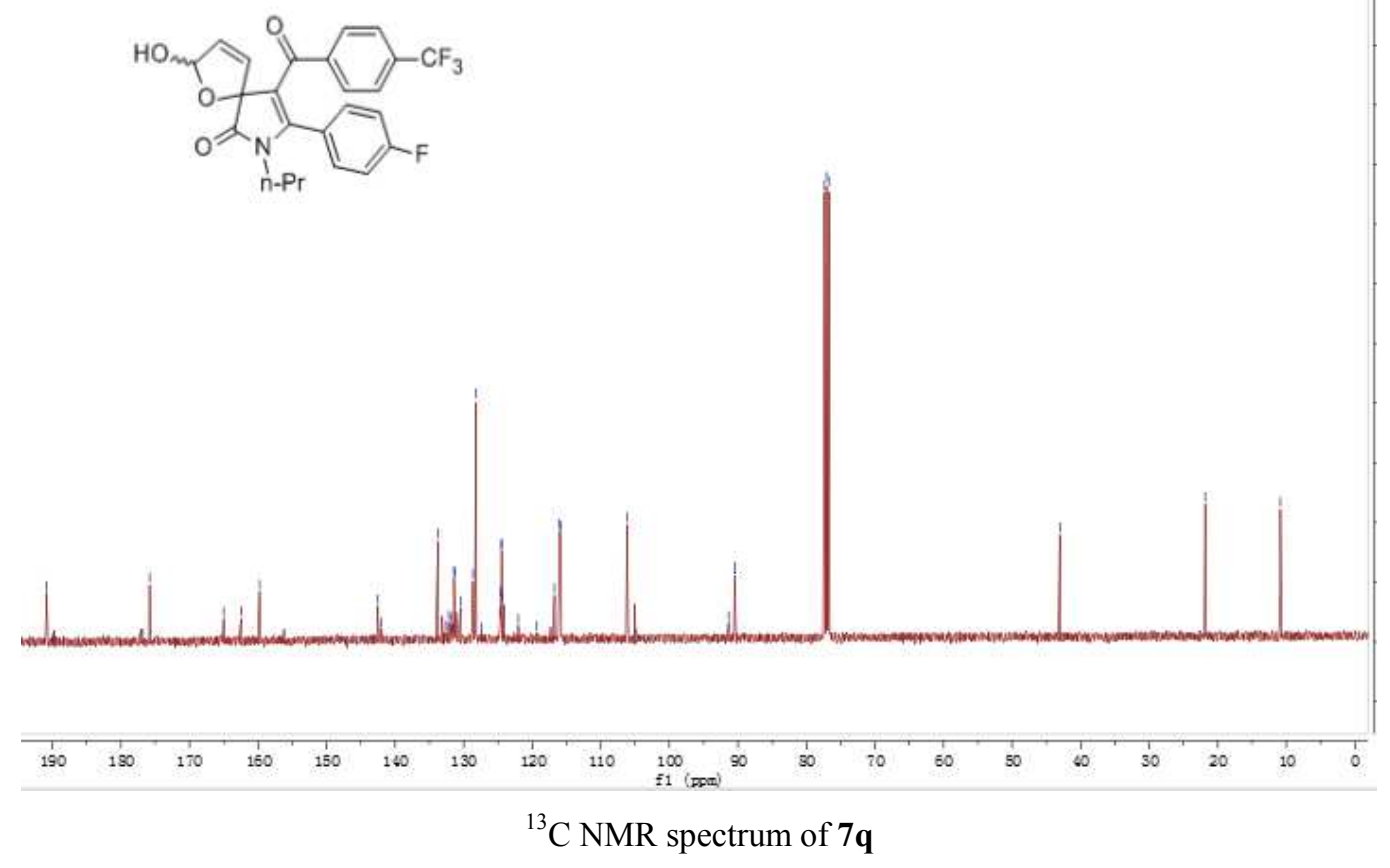

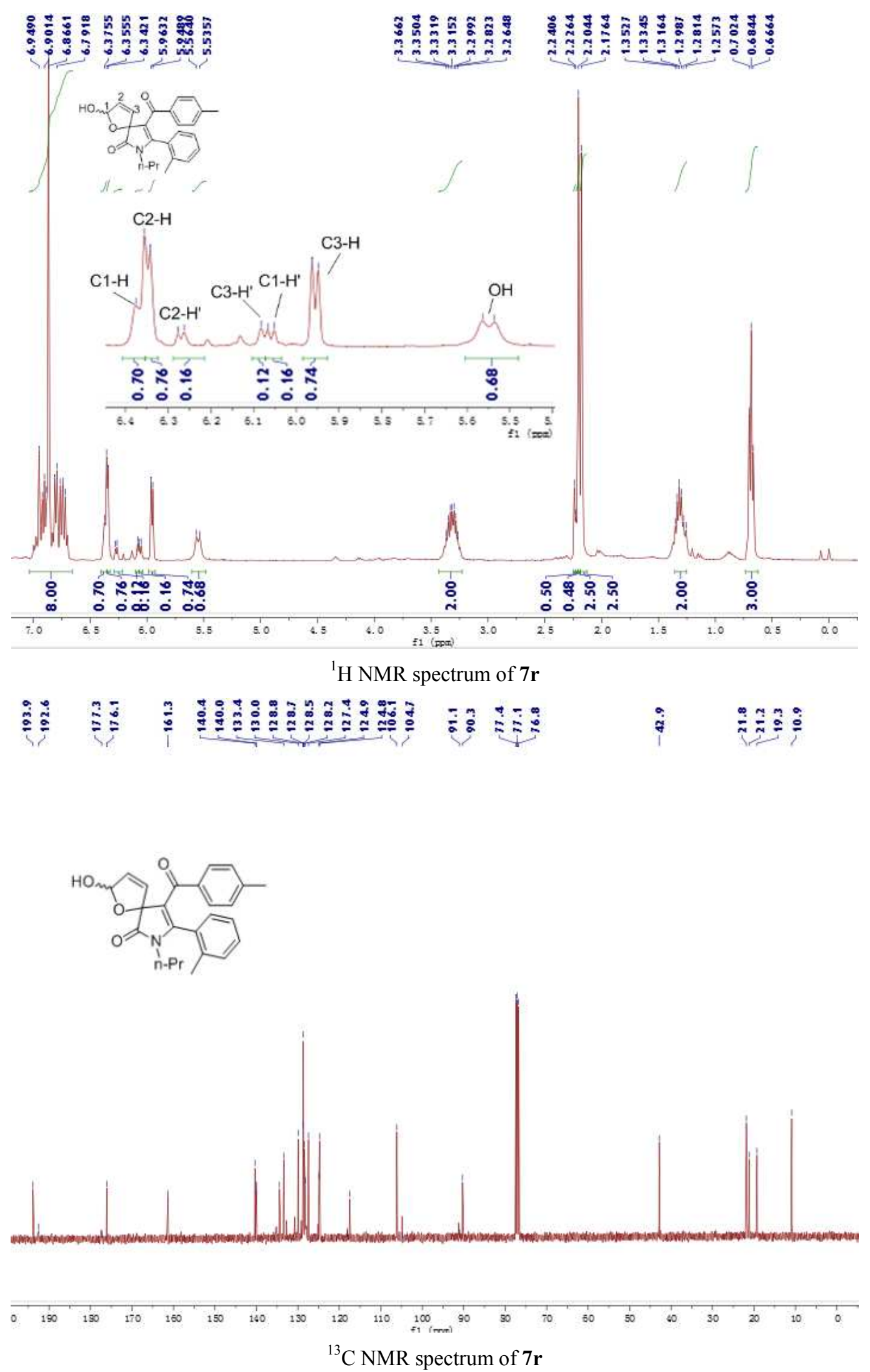


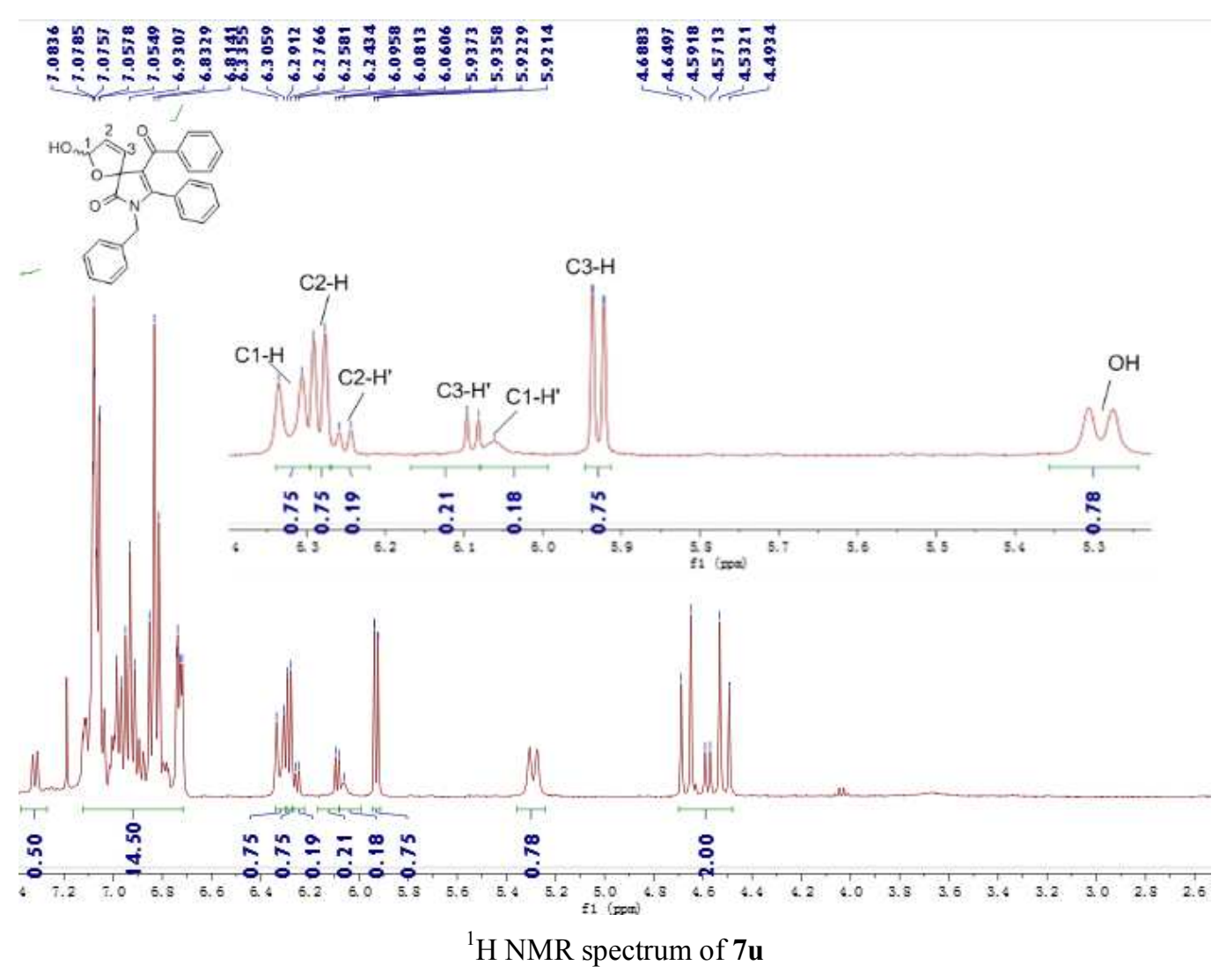

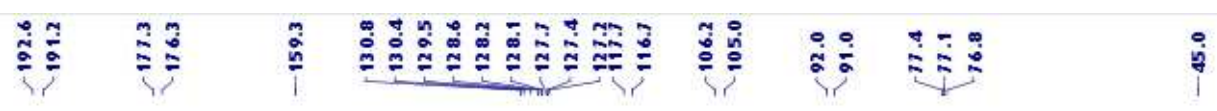

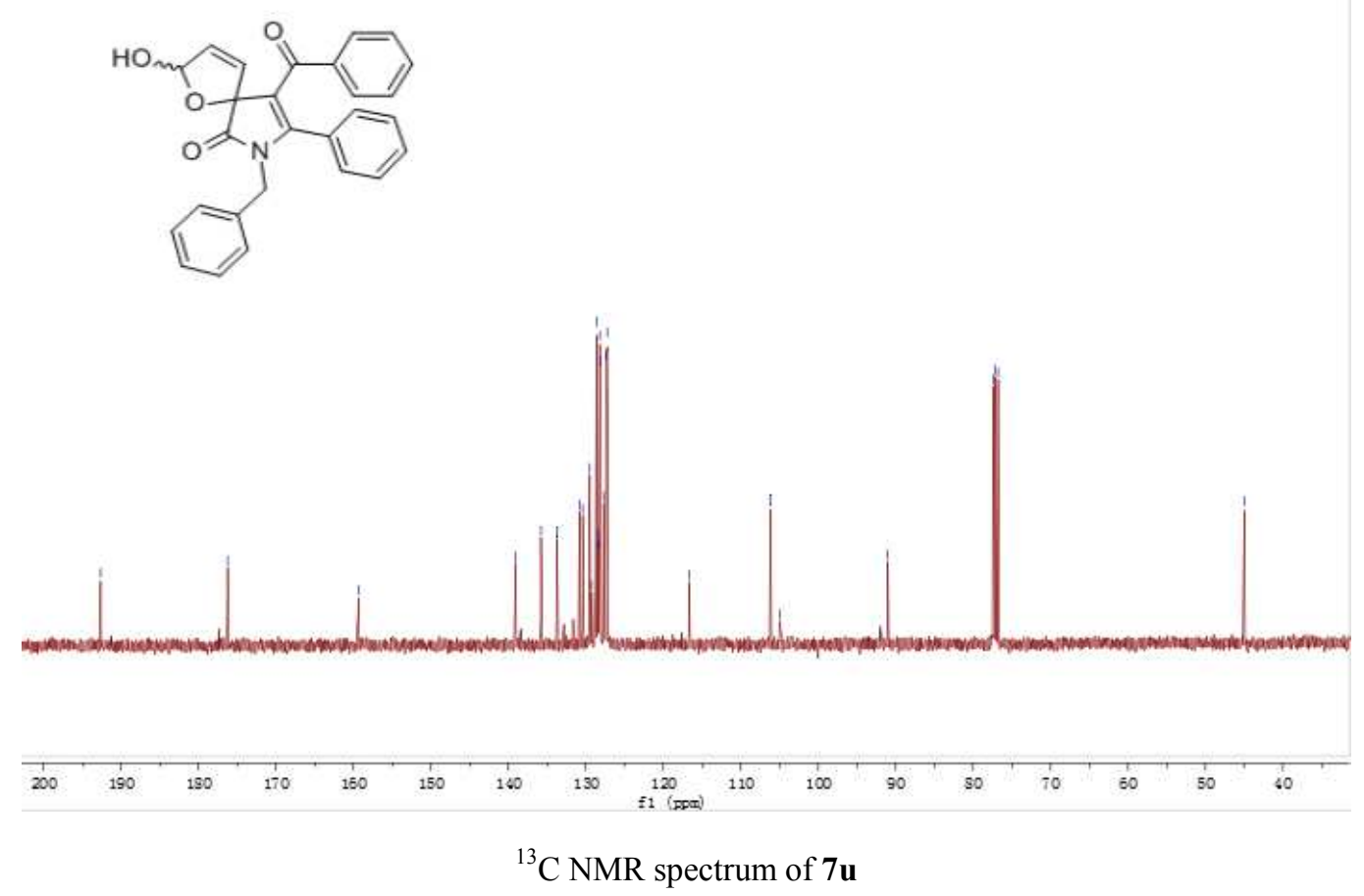




\section{Spectra of $\mathbf{8}$}

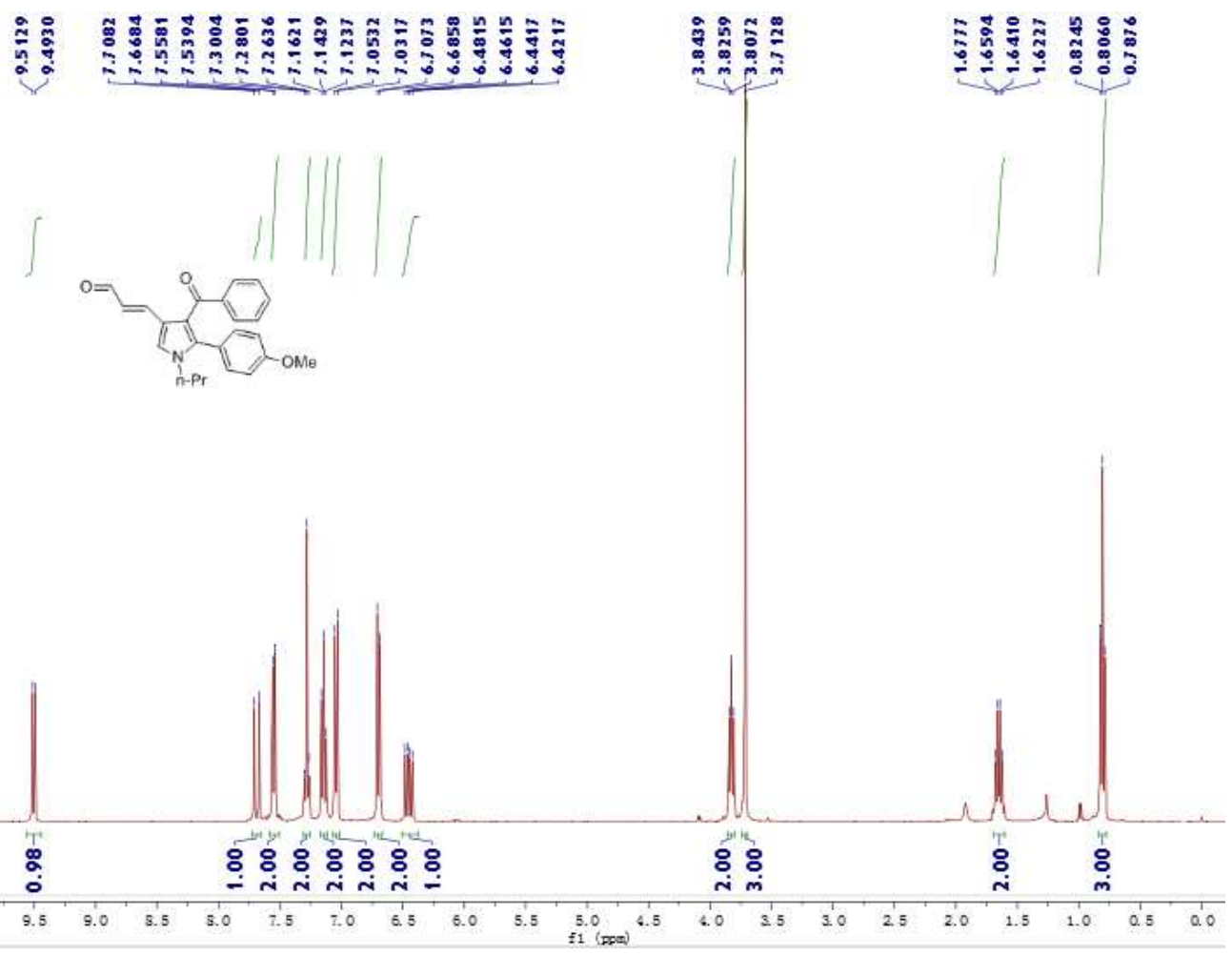

${ }^{1} \mathrm{H}$ NMR spectrum of $\mathbf{8 a}$
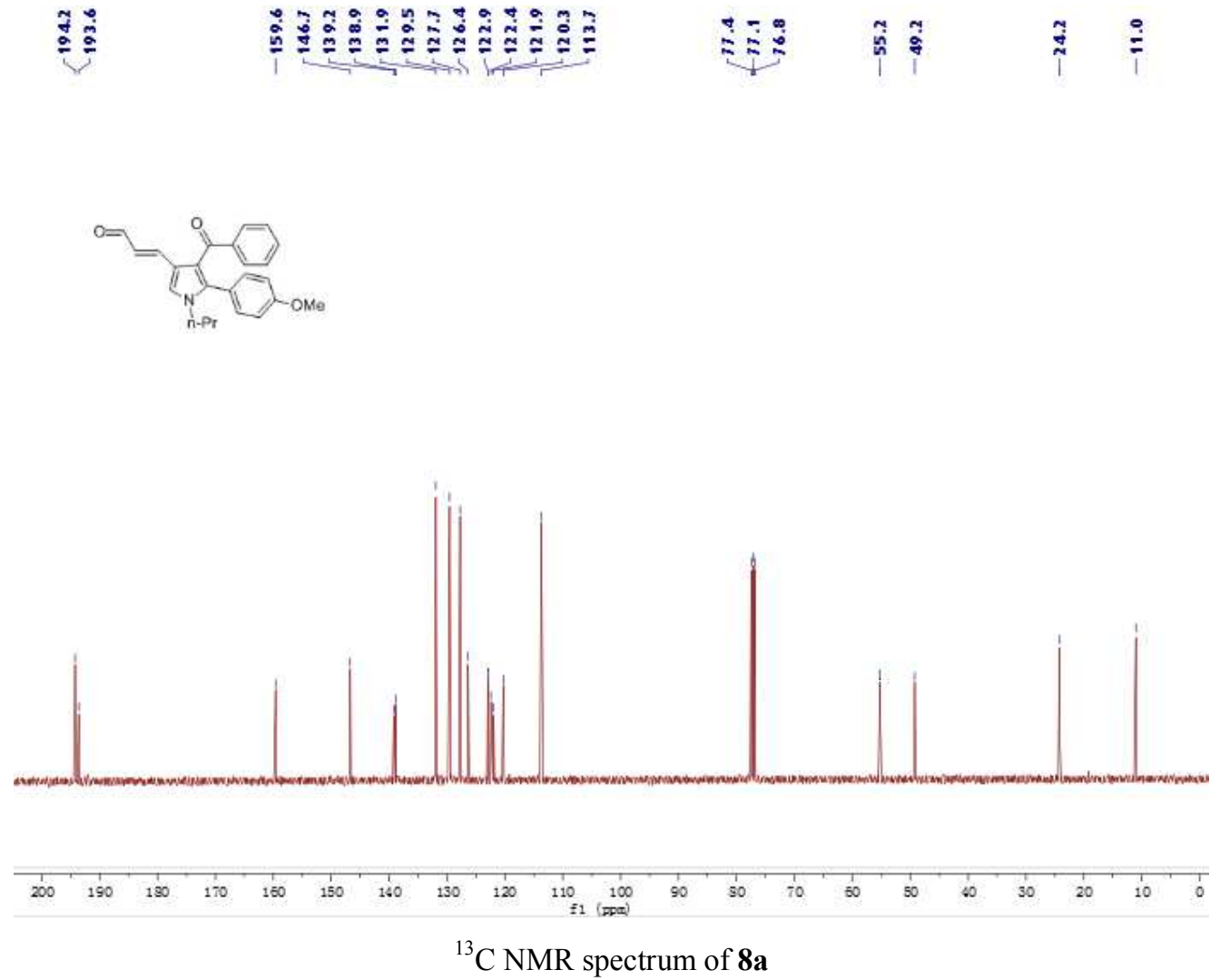


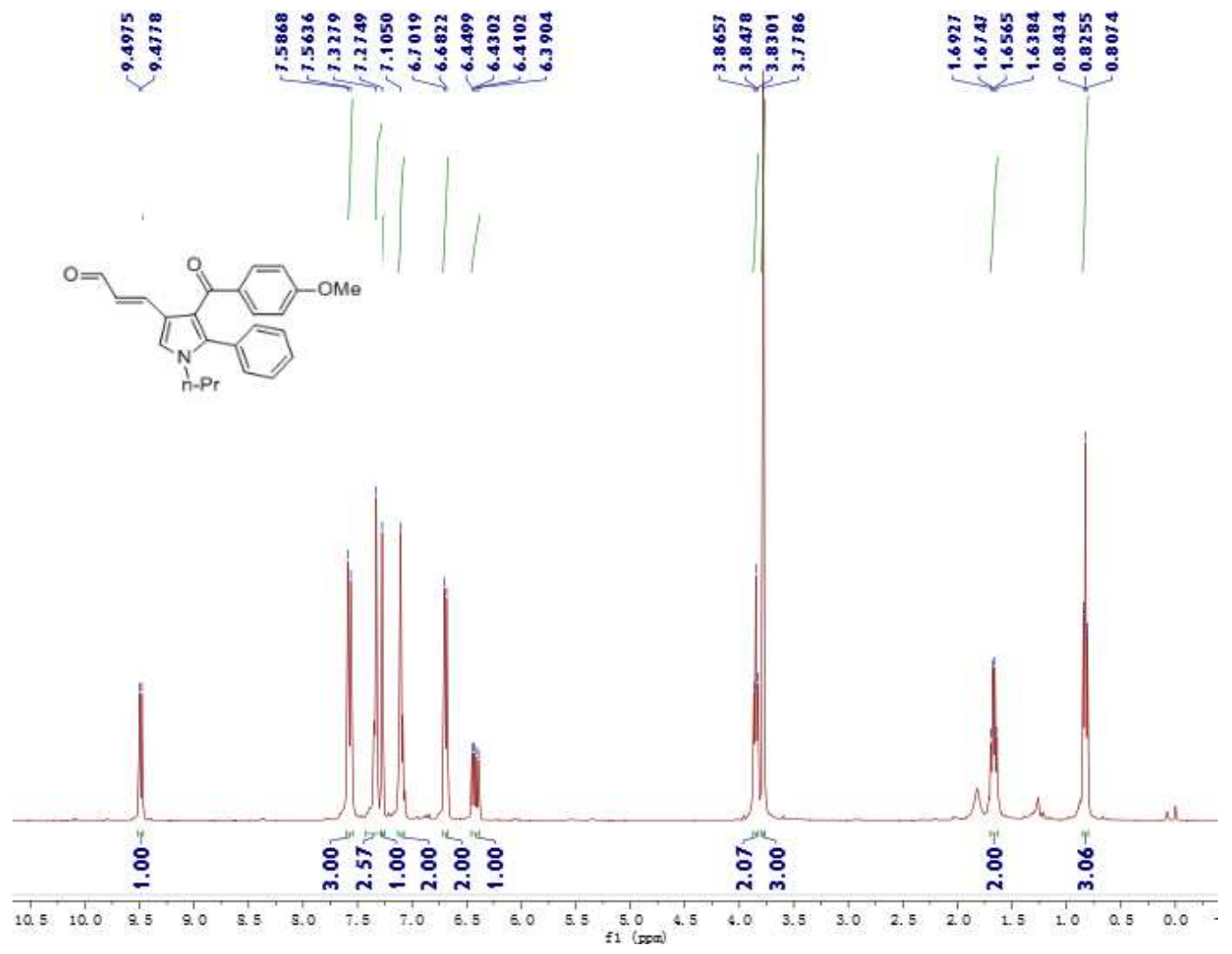

${ }^{1} \mathrm{H}$ NMR spectrum of $\mathbf{8 b}$
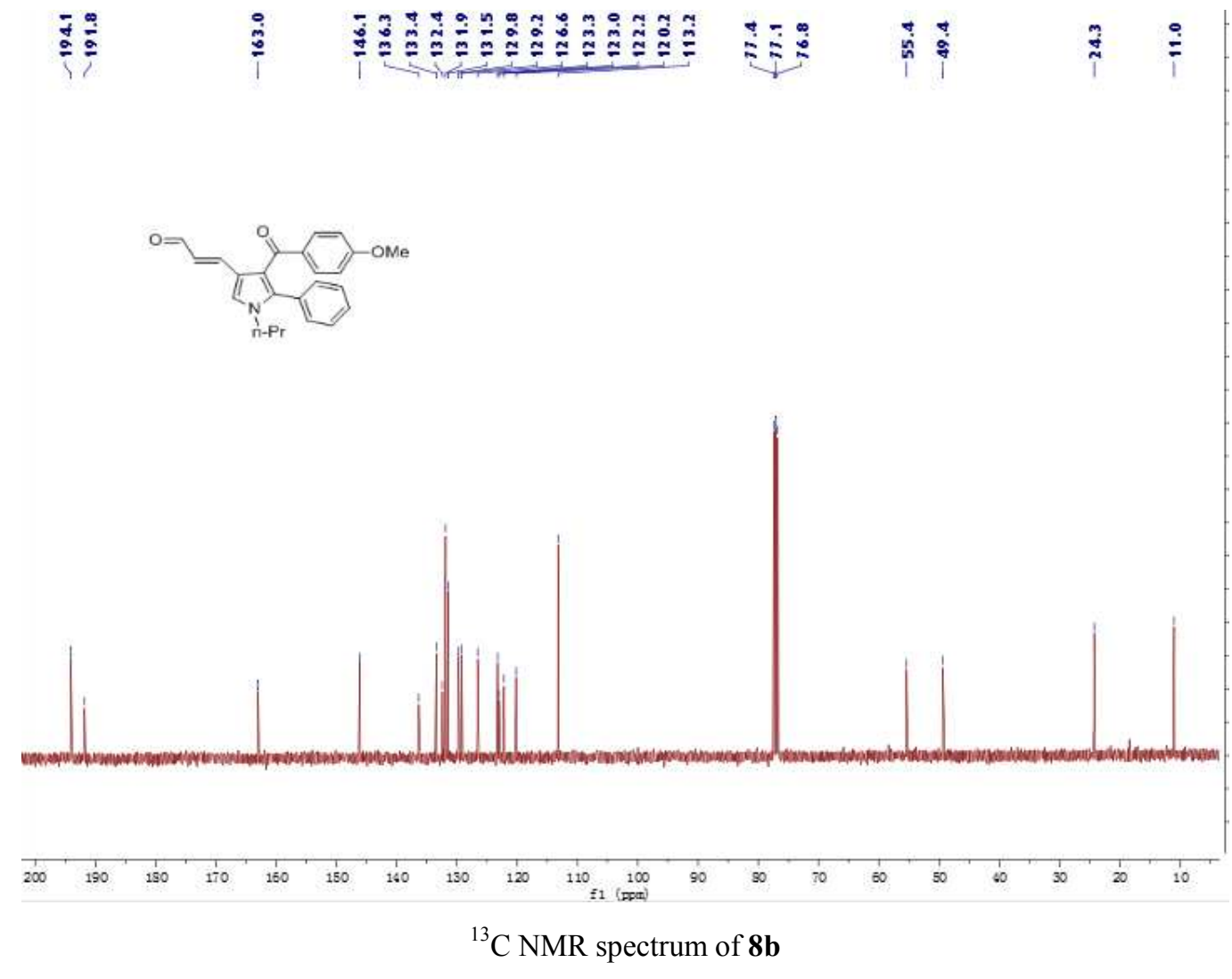

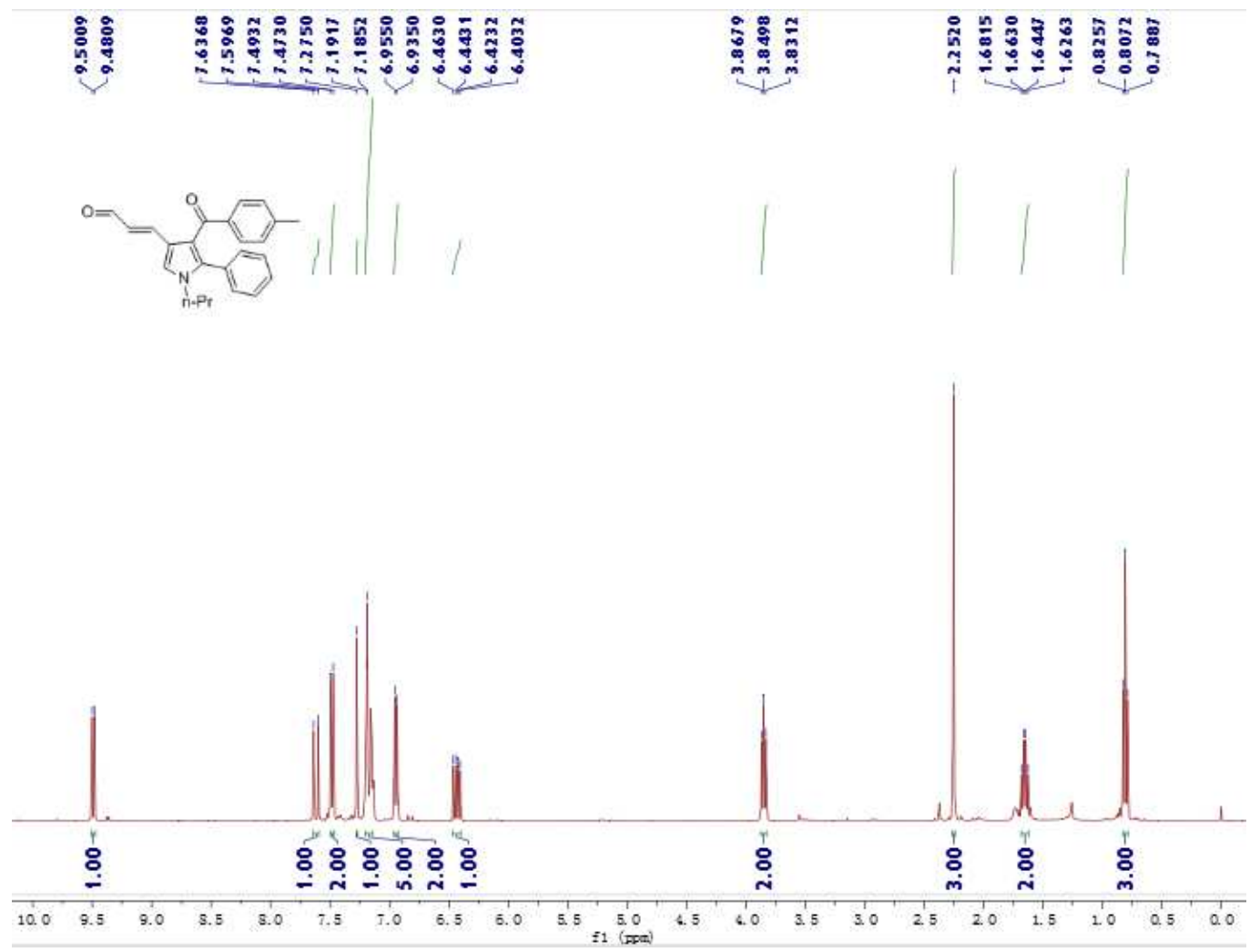

${ }^{1} \mathrm{H}$ NMR spectrum of $\mathbf{8 c}$

$\stackrel{7}{\frac{7}{2}}$

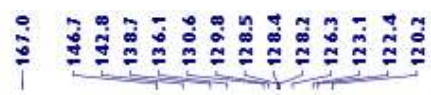

$\stackrel{n}{=}$

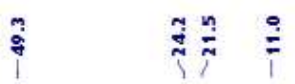

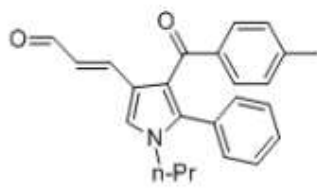
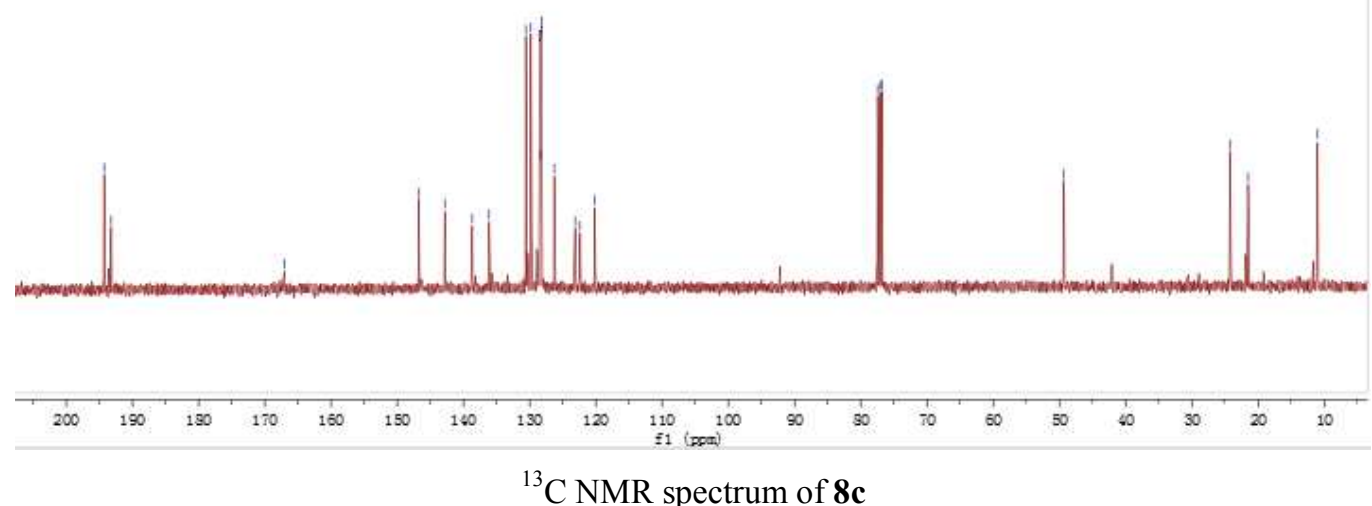


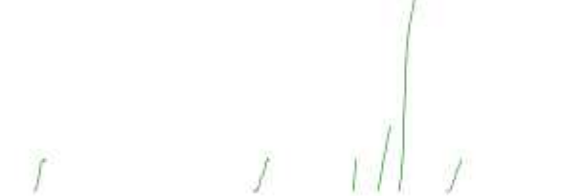

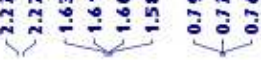
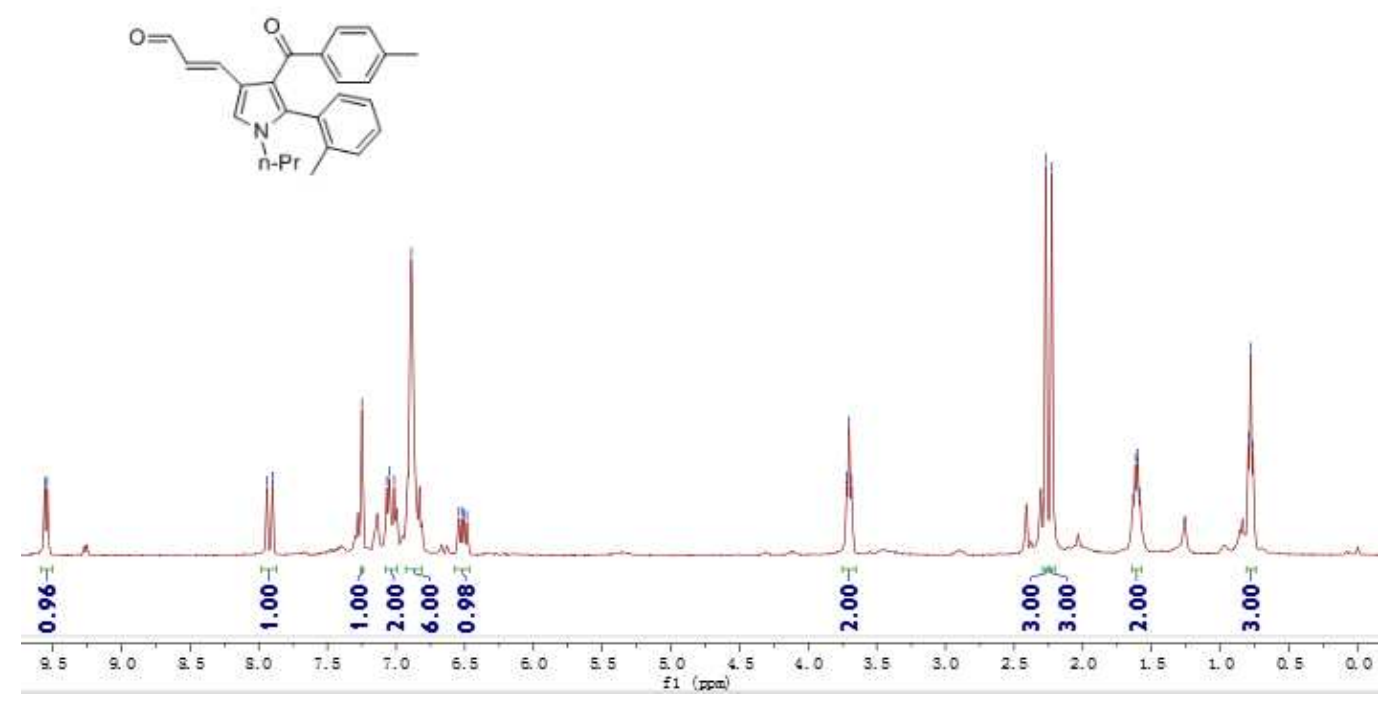

${ }^{1} \mathrm{H}$ NMR spectrum of $\mathbf{8 d}$
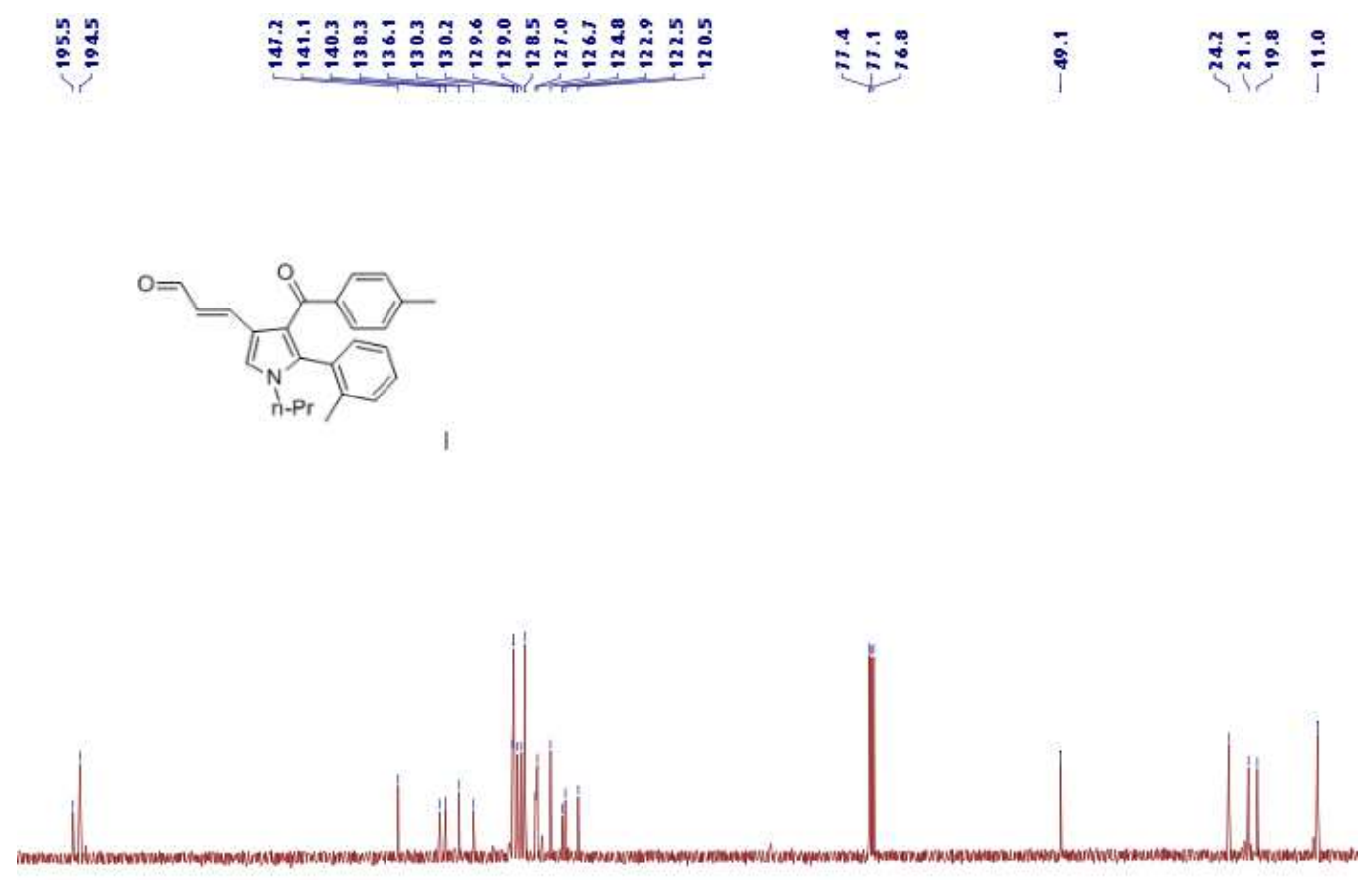

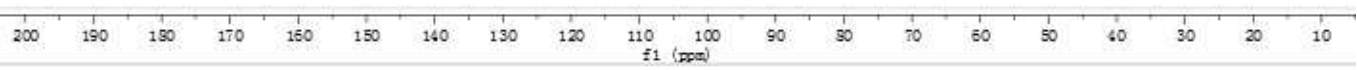

${ }^{13} \mathrm{C}$ NMR spectrum of $\mathbf{8 d}$ 


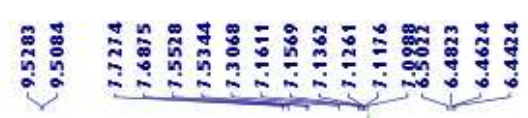

:

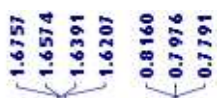
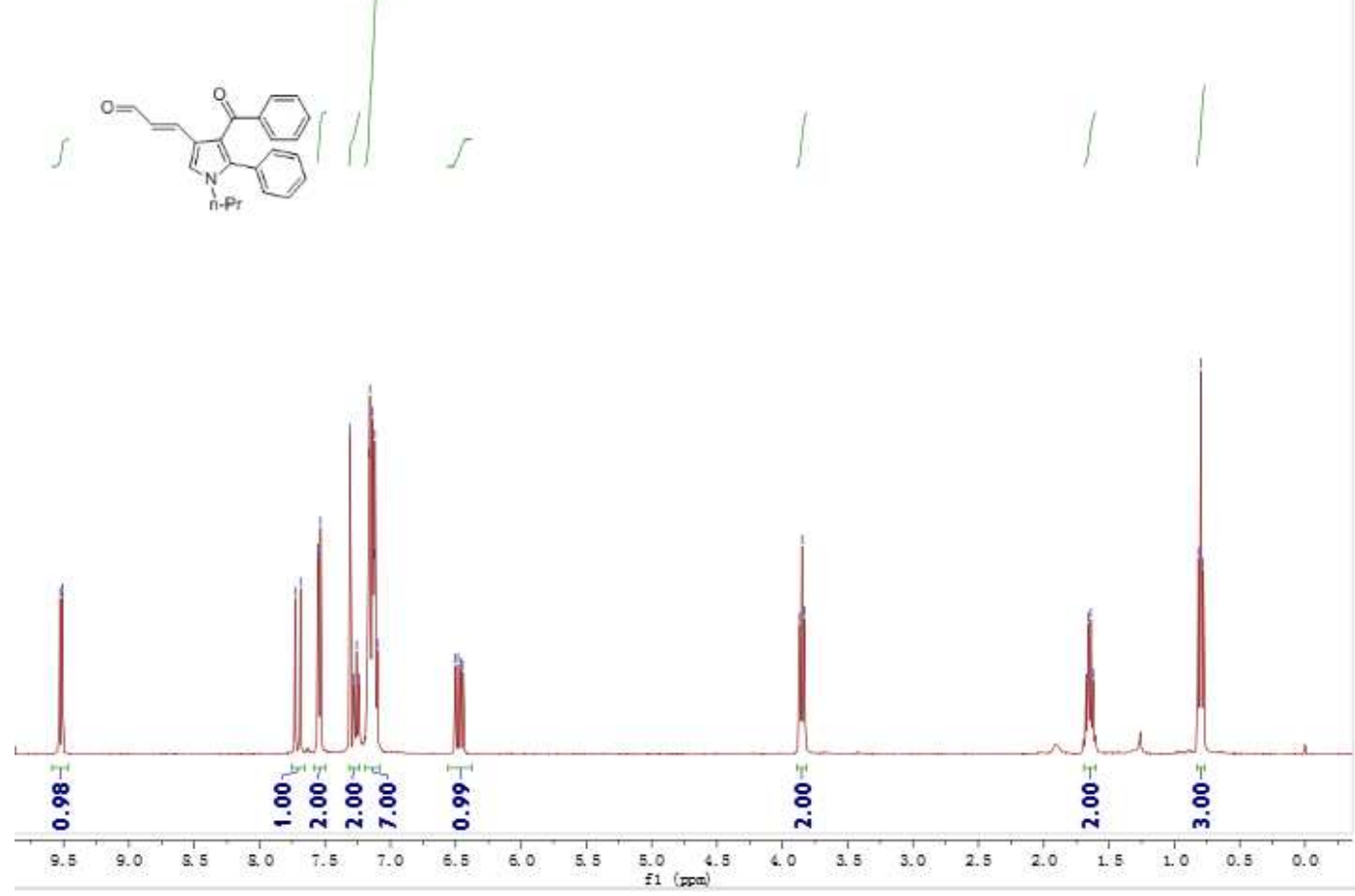

${ }^{1} \mathrm{H}$ NMR spectrum of $\mathbf{8 e}$

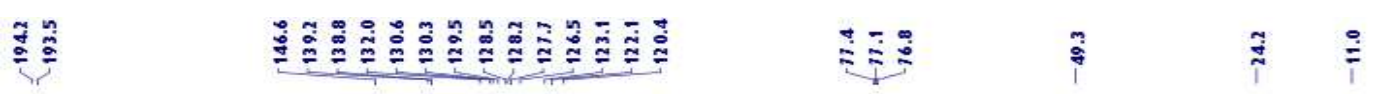
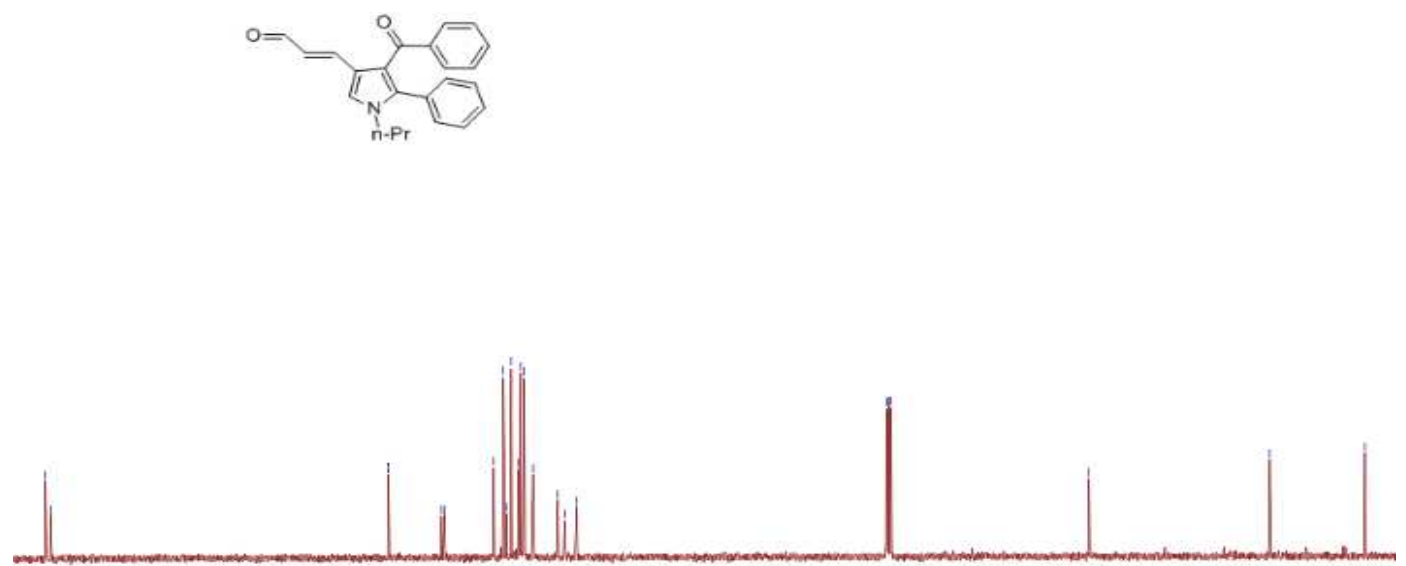

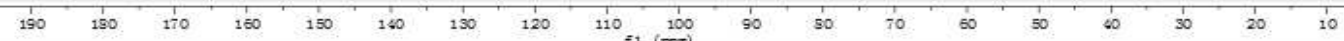

${ }^{13} \mathrm{C}$ NMR spectrum of $\mathbf{8 e}$ 


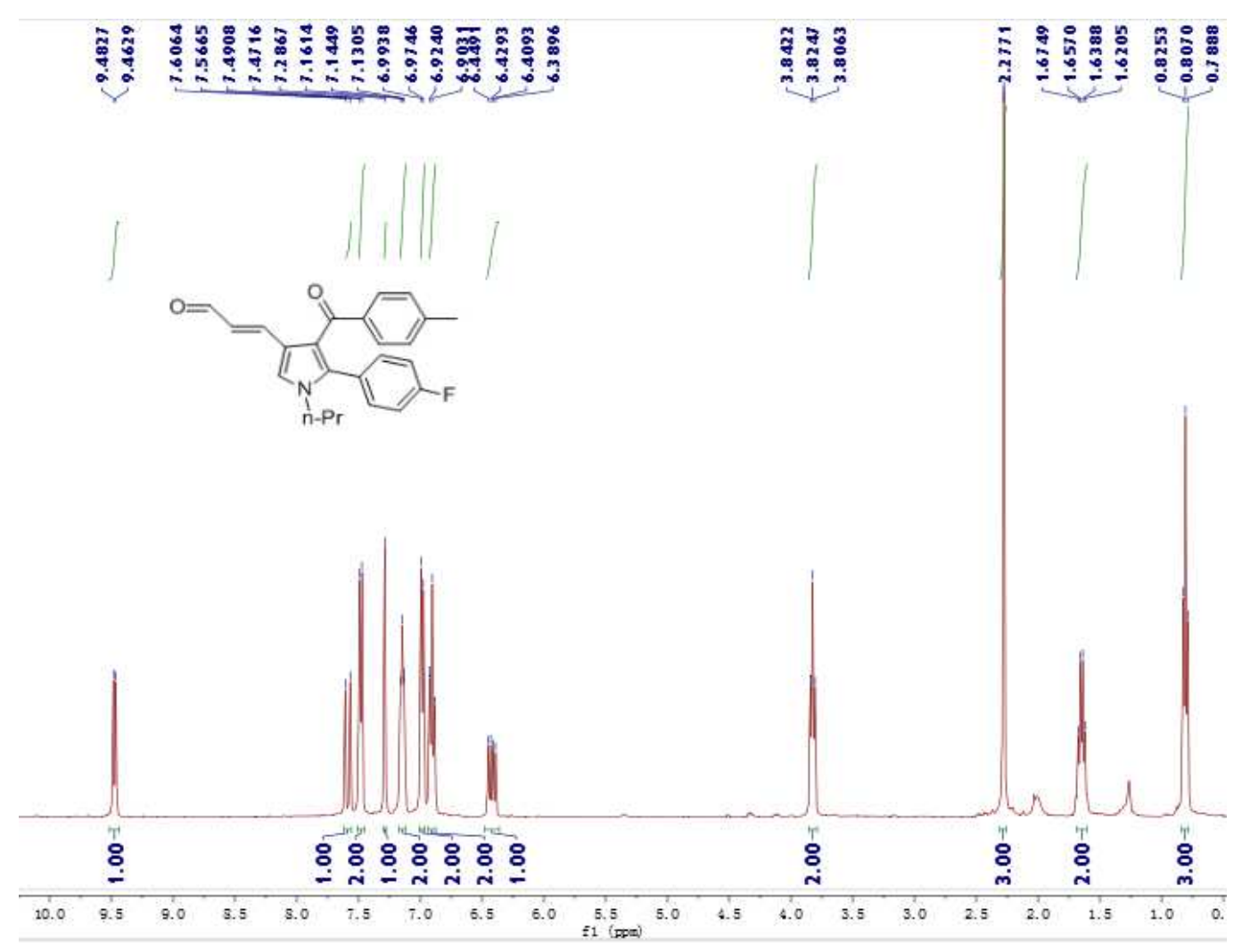

${ }^{1} \mathrm{H}$ NMR spectrum of $8 \mathbf{8}$
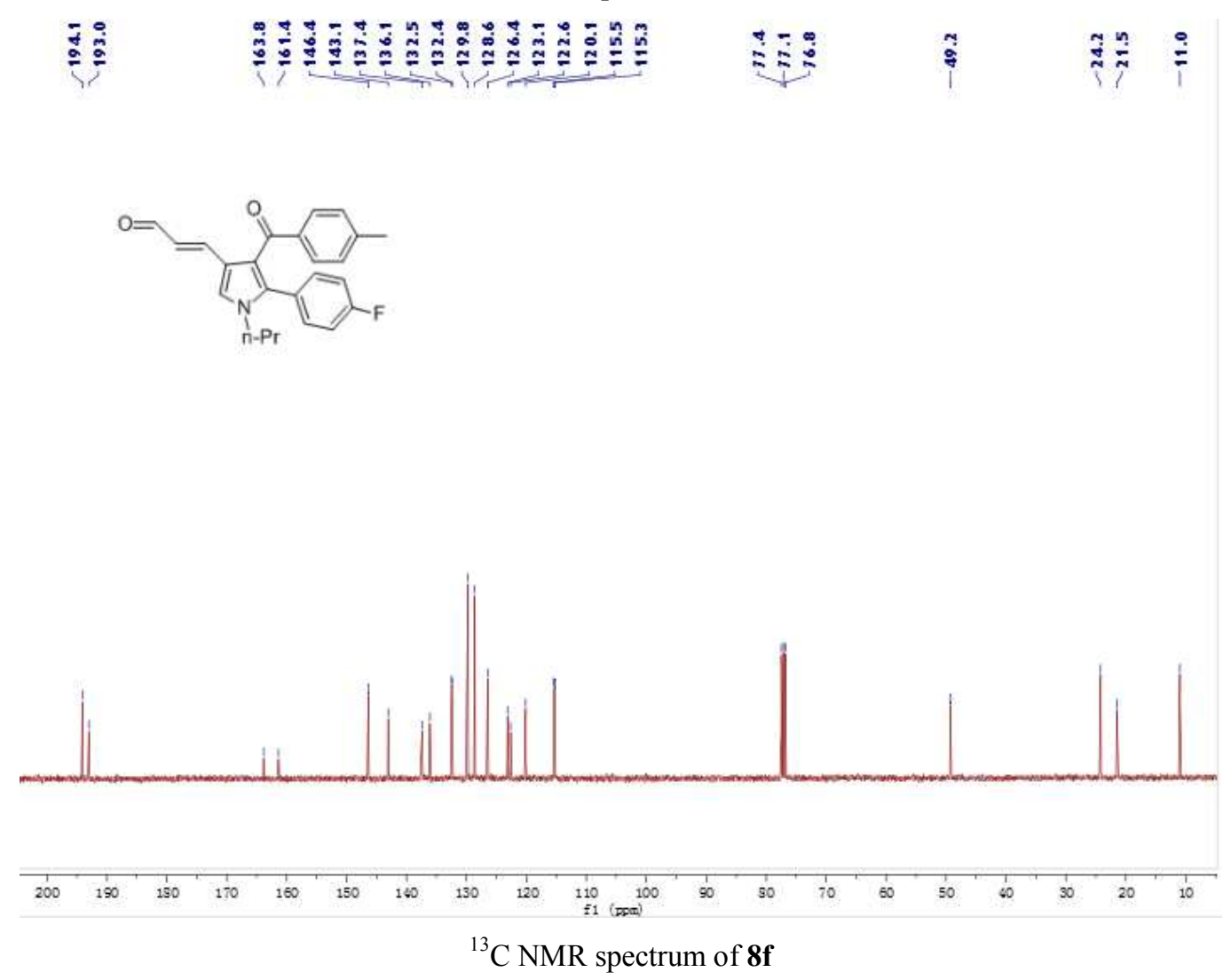

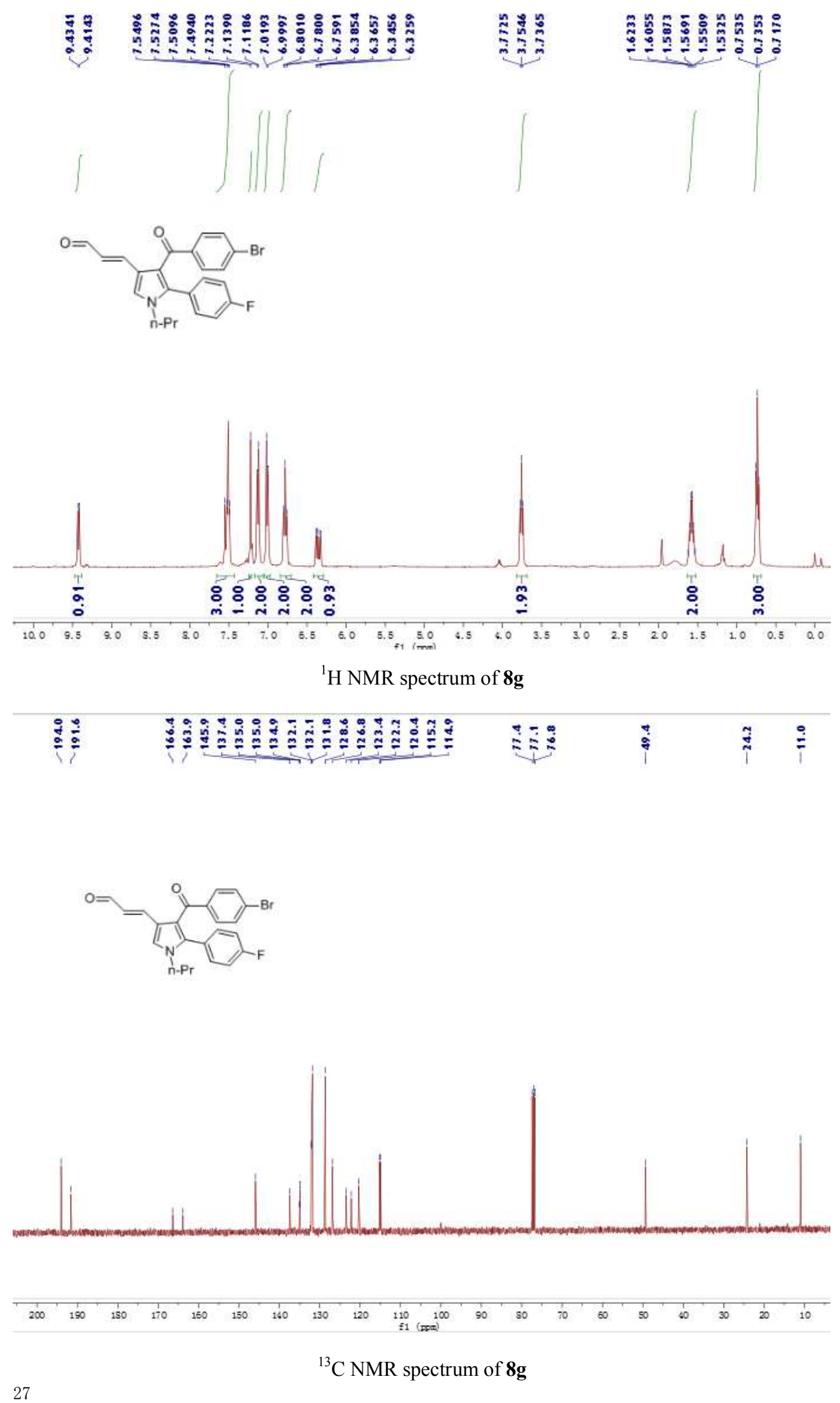

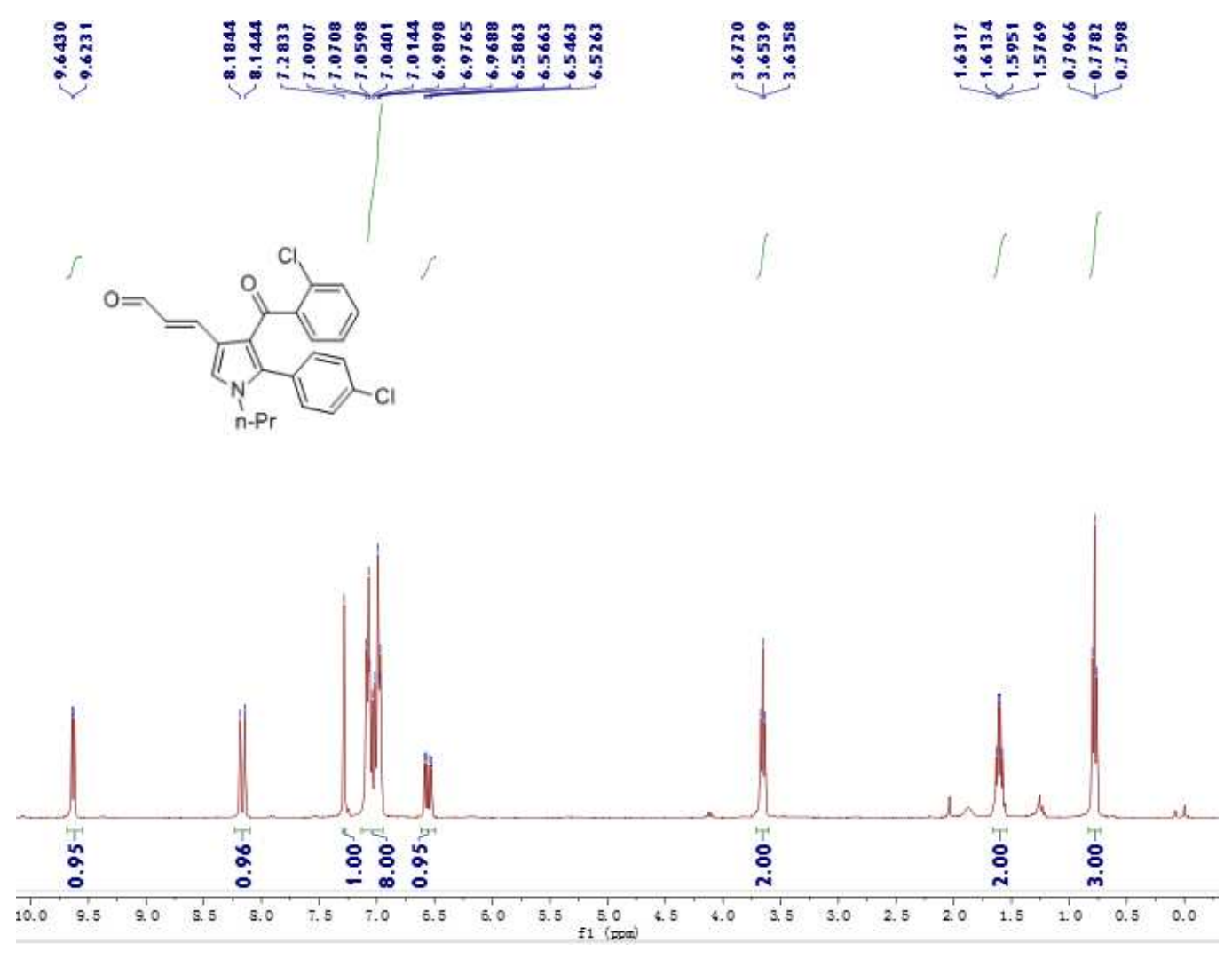

${ }^{1}$ H NMR spectrum of $\mathbf{8 h}$
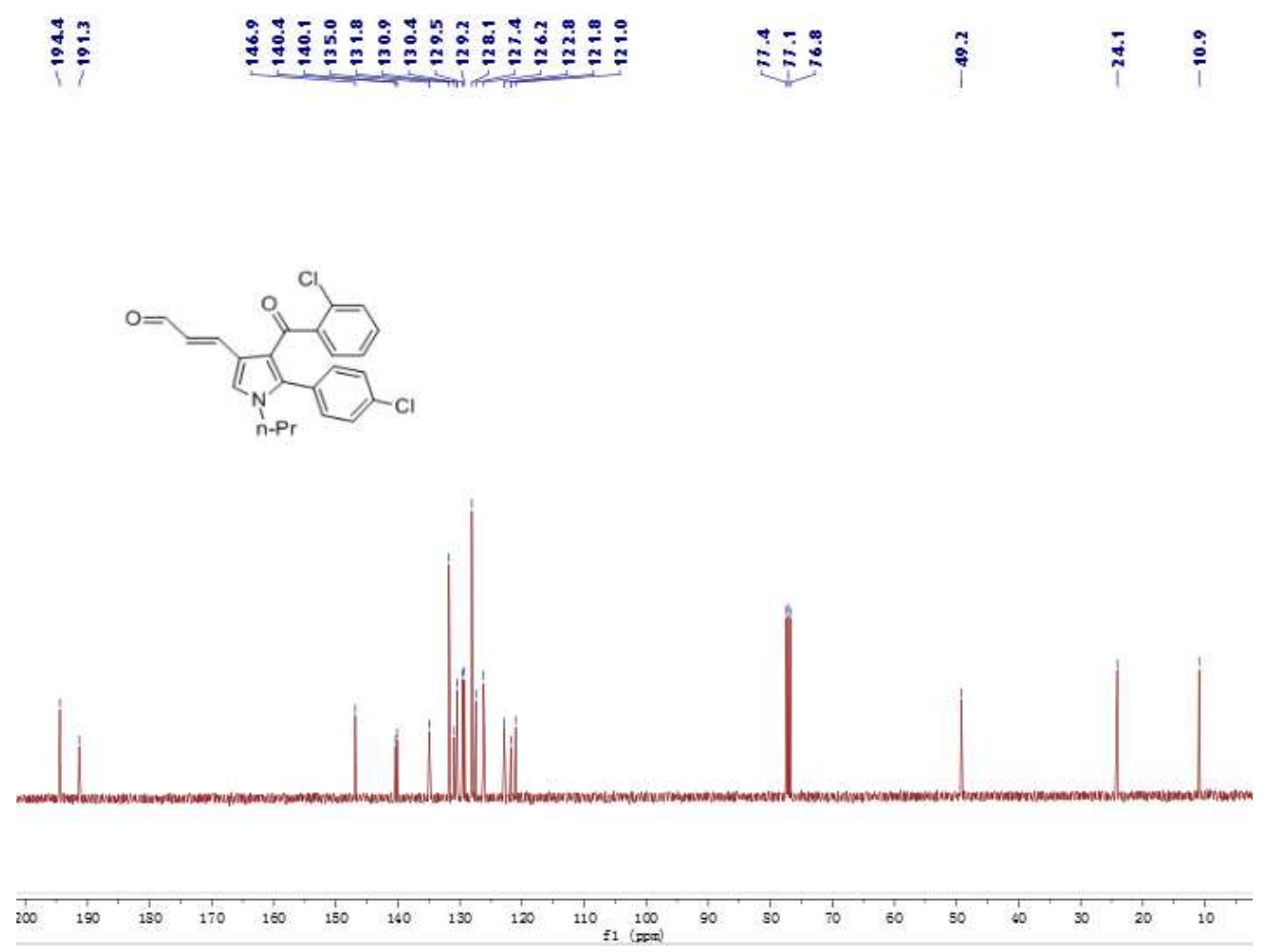

${ }^{13} \mathrm{C}$ NMR spectrum of $\mathbf{8 h}$ 


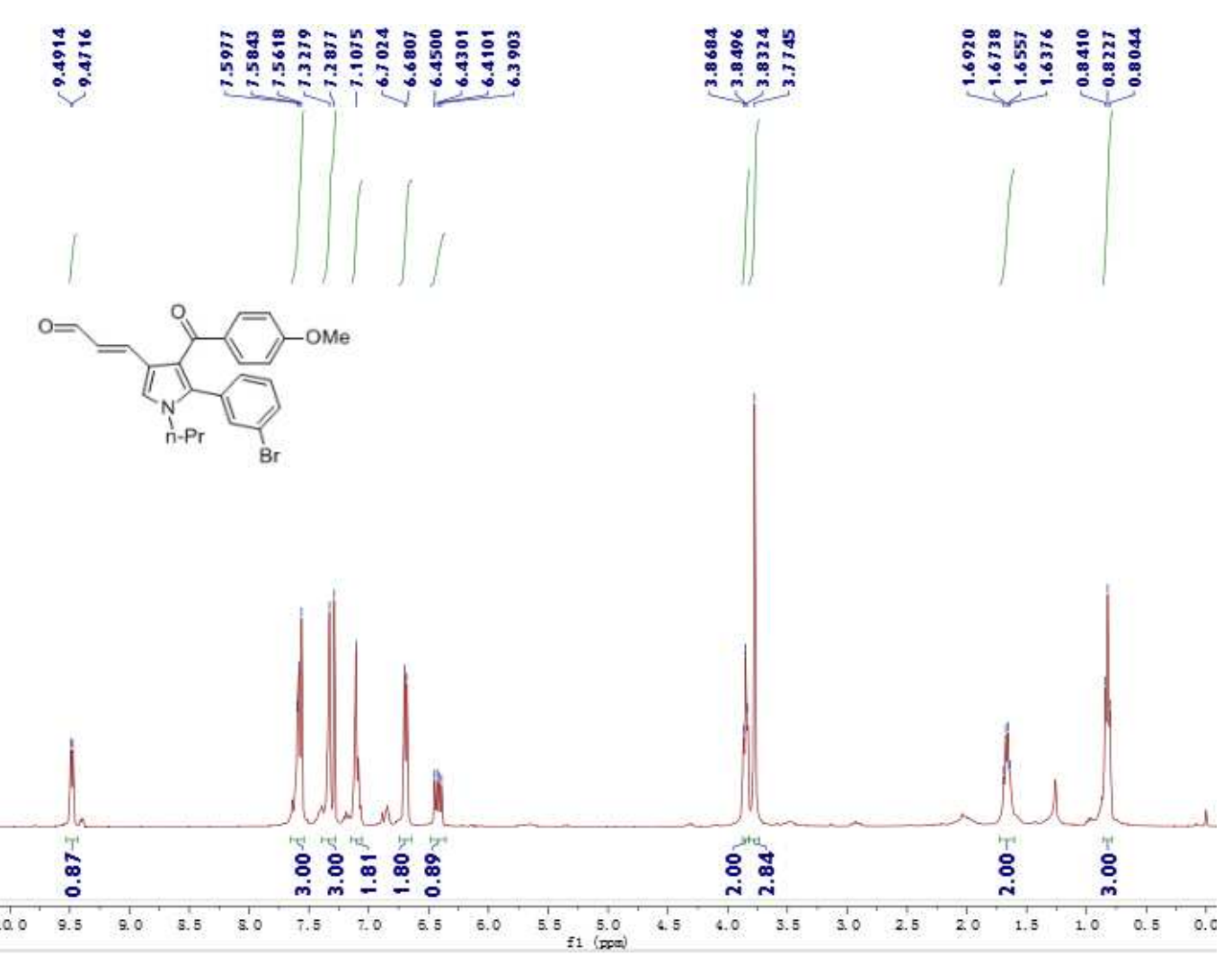

${ }^{1} \mathrm{H}$ NMR spectrum of $\mathbf{8 i}$
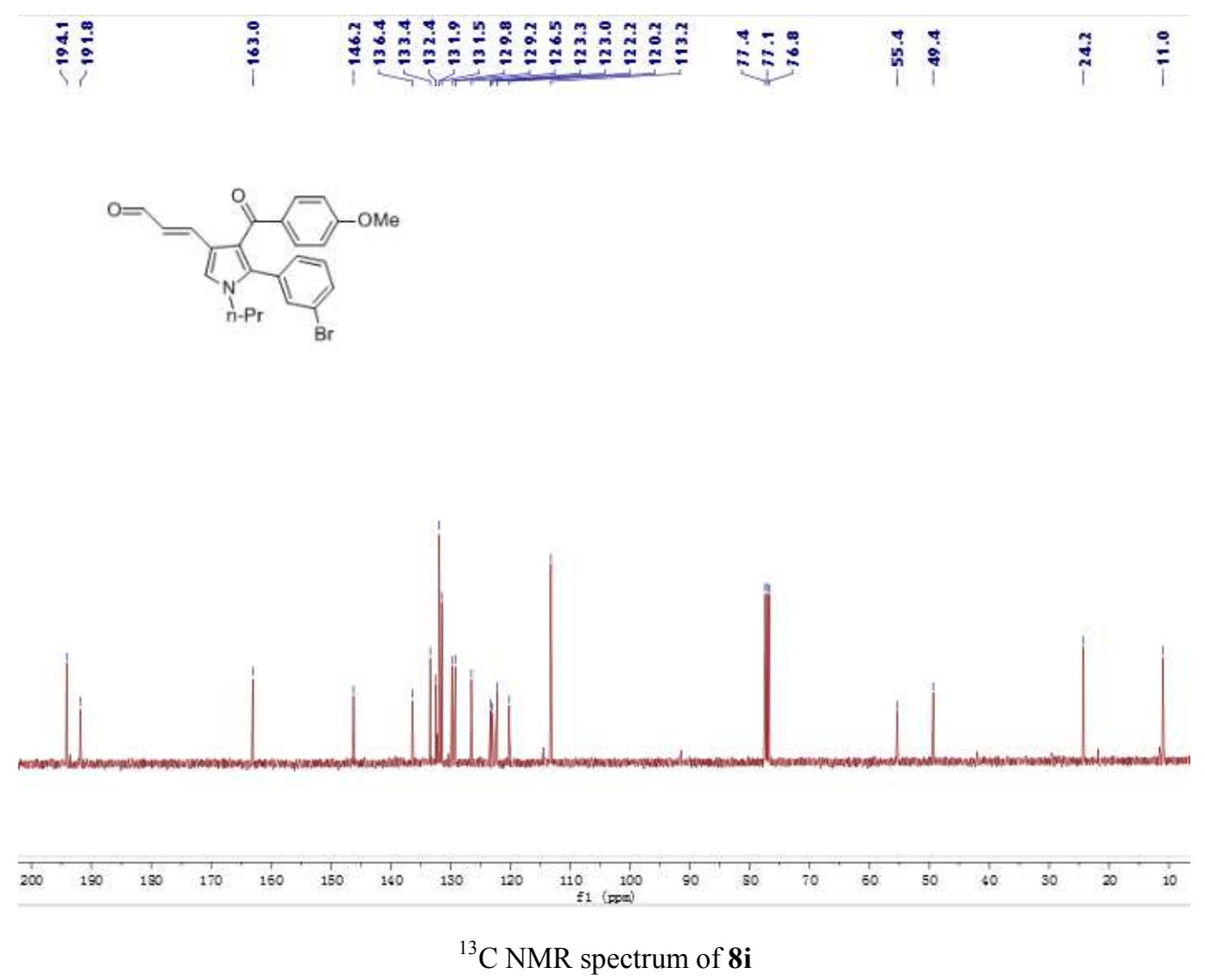

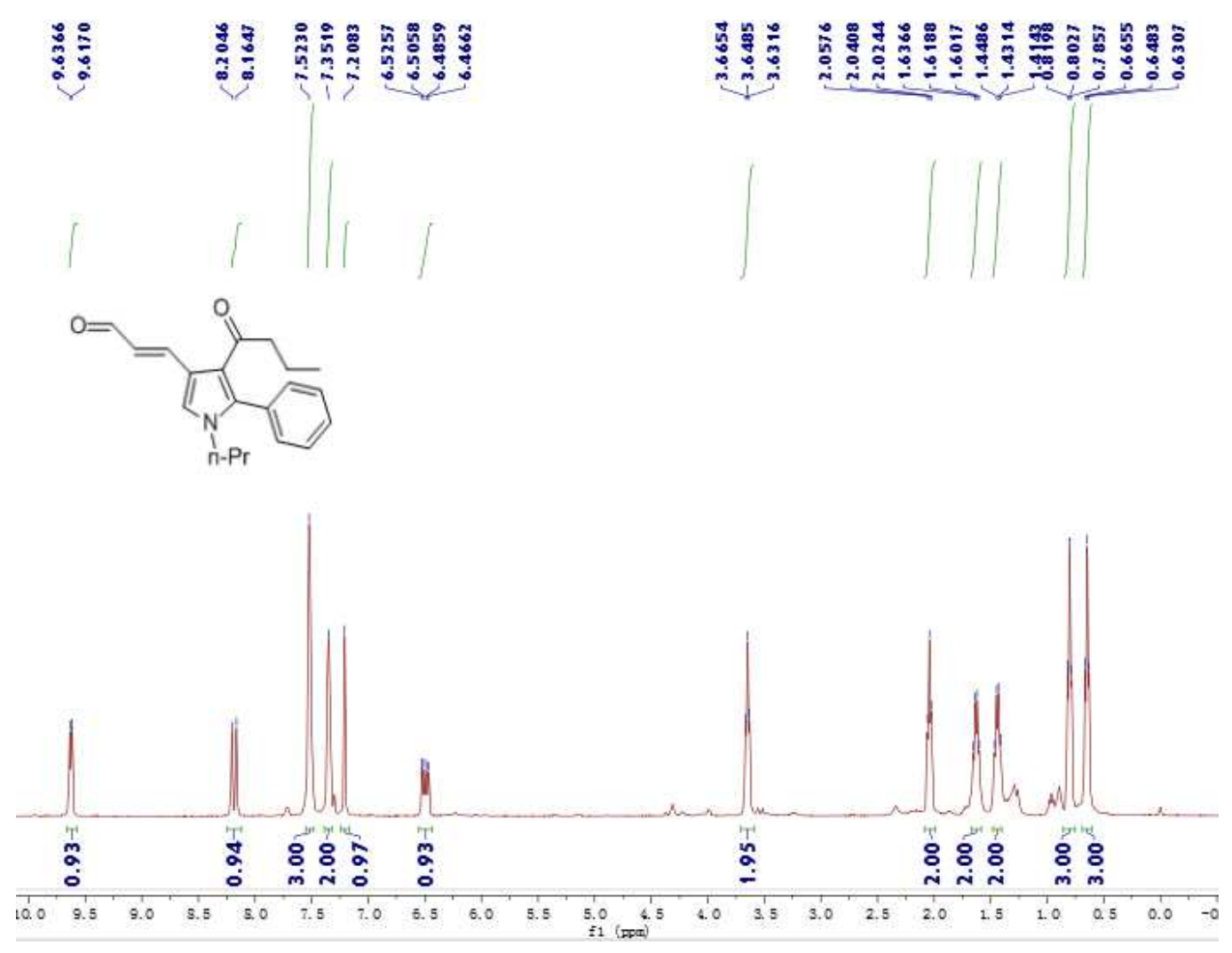

${ }^{1} \mathrm{H}$ NMR spectrum of $\mathbf{8 j}$
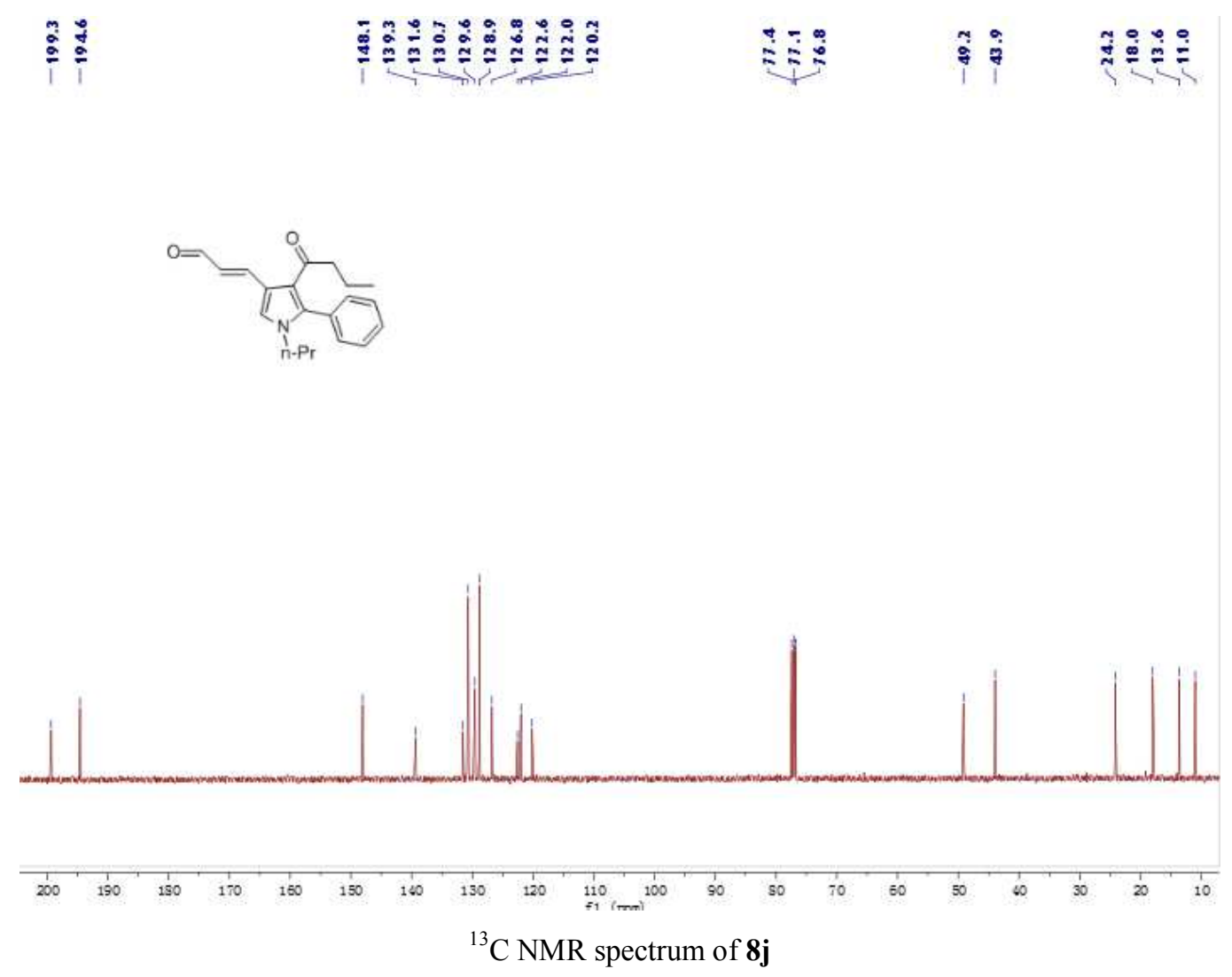


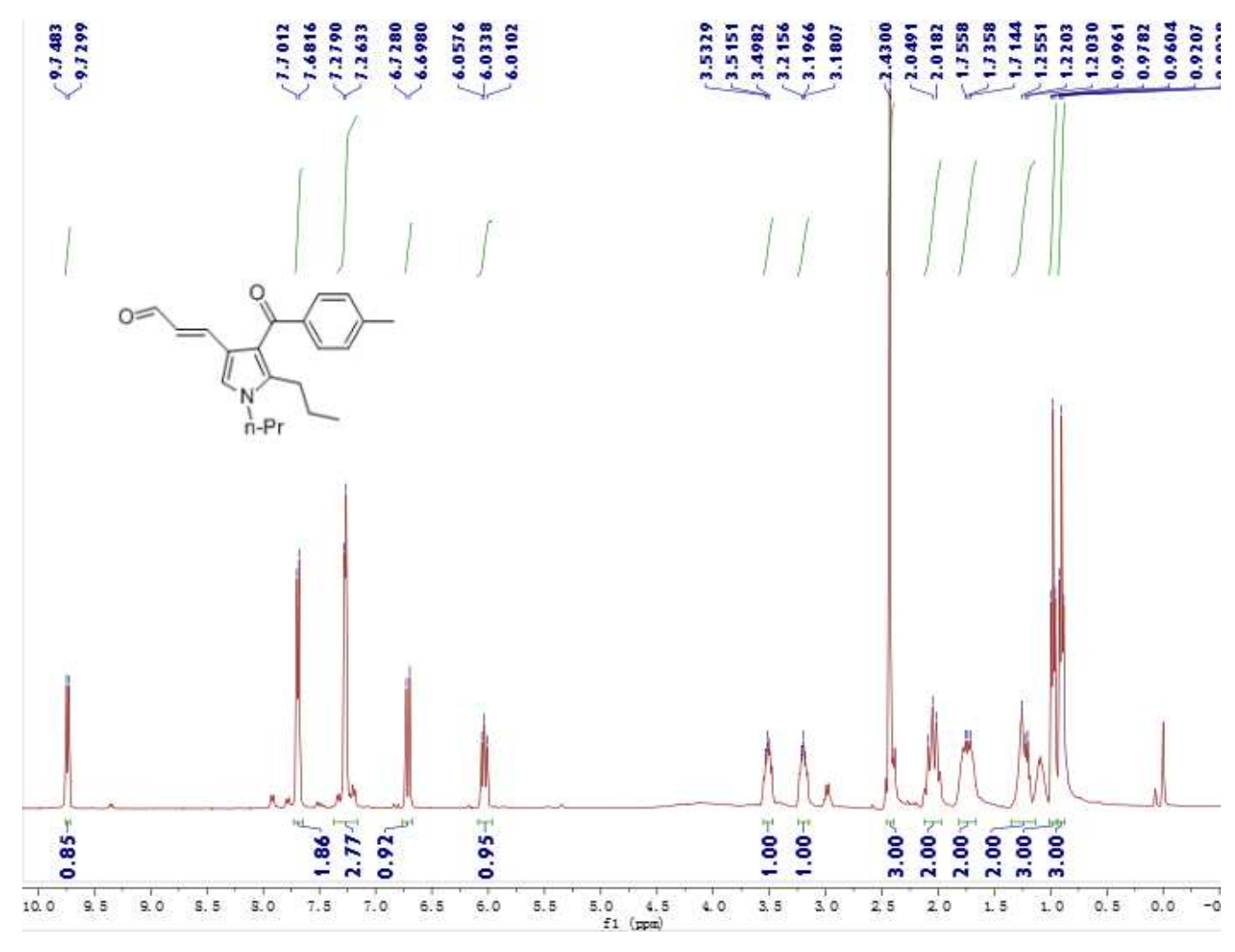

${ }^{1} \mathrm{H}$ NMR spectrum of $\mathbf{8 k}$
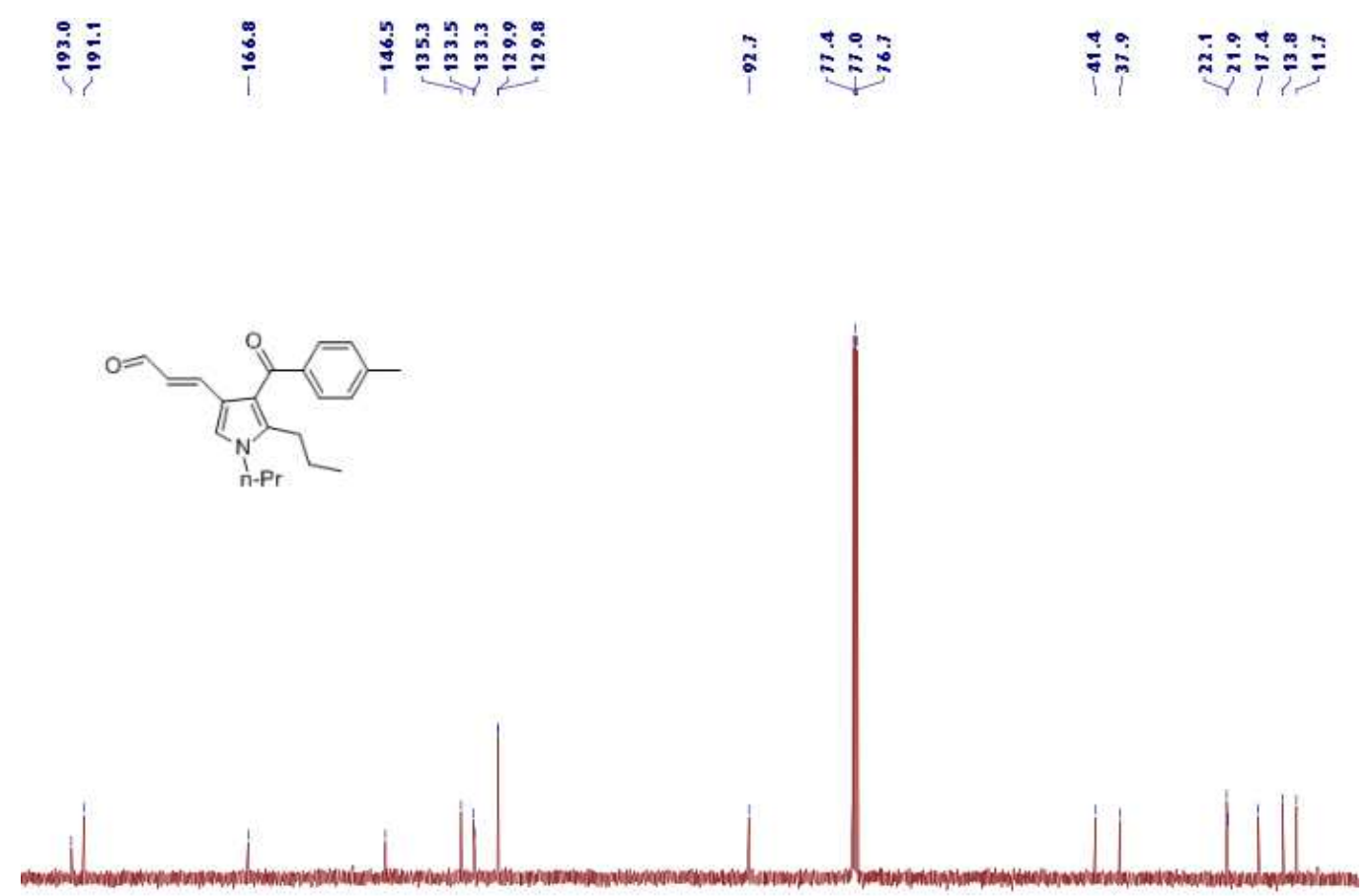

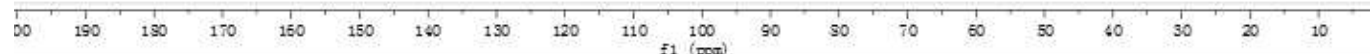

${ }^{13} \mathrm{C}$ NMR spectrum of $\mathbf{8 k}$ 

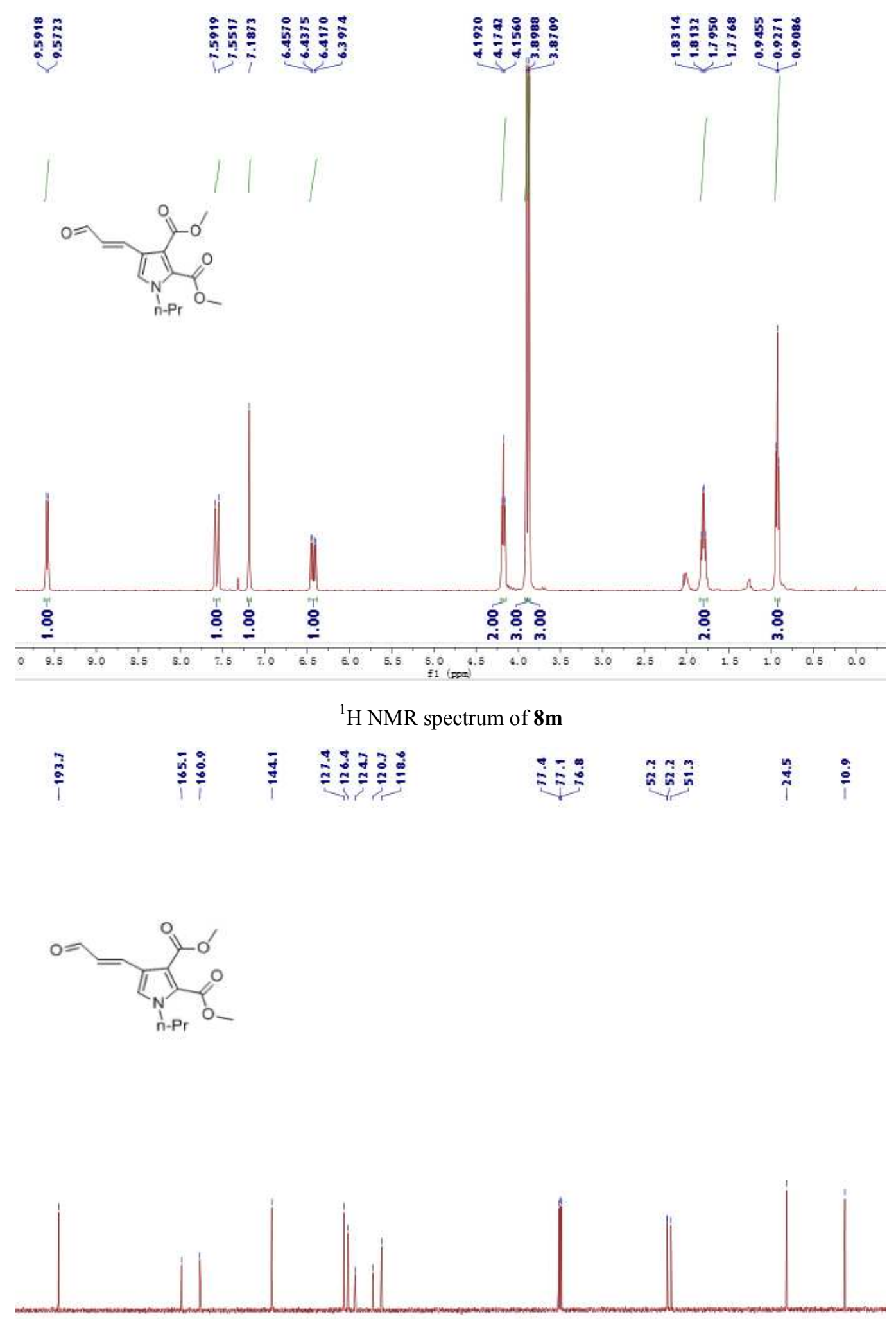

\begin{tabular}{|c|c|c|c|c|c|c|c|c|c|c|c|c|c|c|c|c|c|c|}
\hline 200 & 190 & 180 & 170 & 160 & 150 & 140 & 130 & 120 & ${ }_{f 1}^{110} 100$ & 90 & so & 70 & 60 & 50 & 40 & 30 & 20 & 10 \\
\hline
\end{tabular}



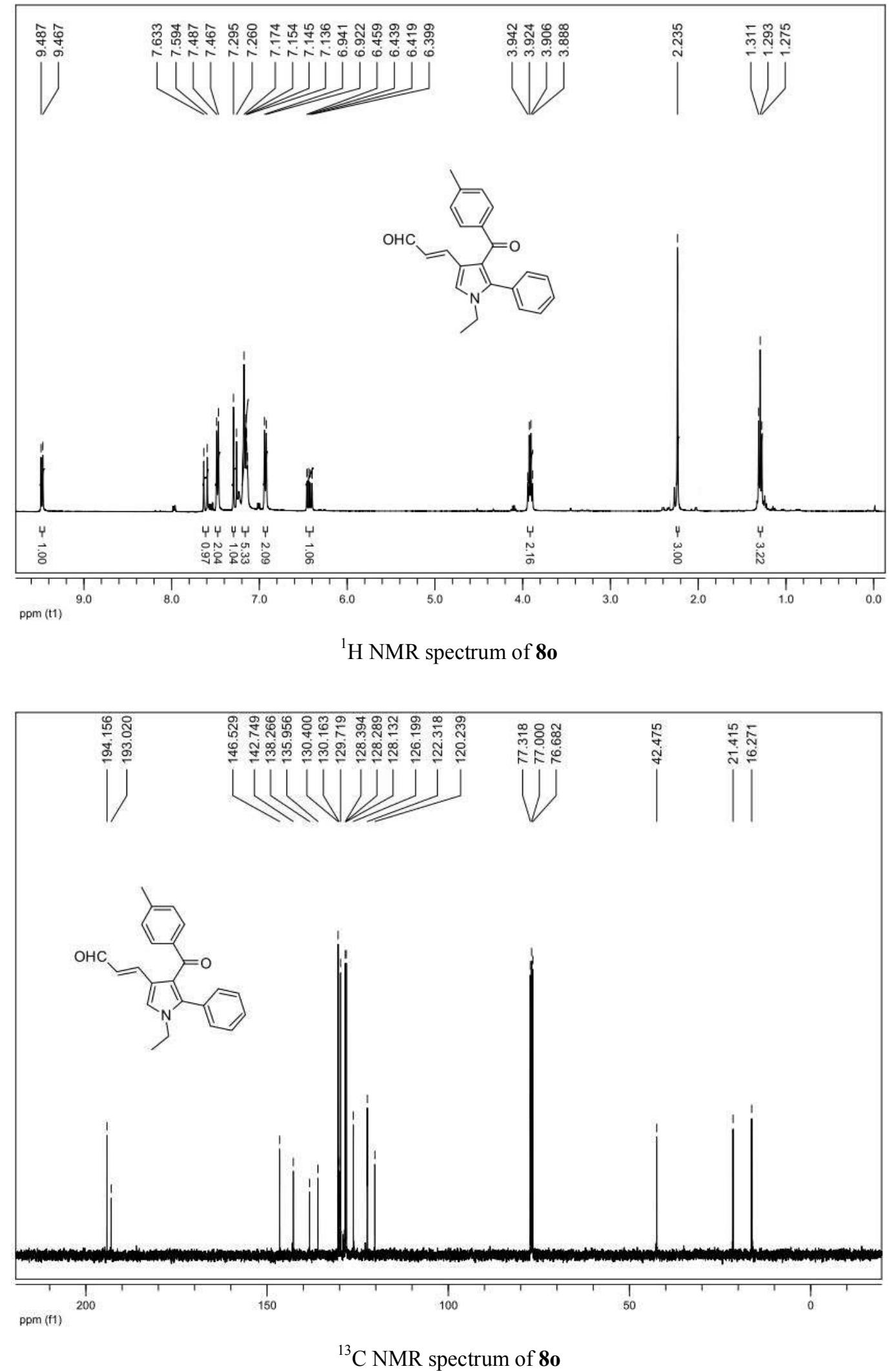


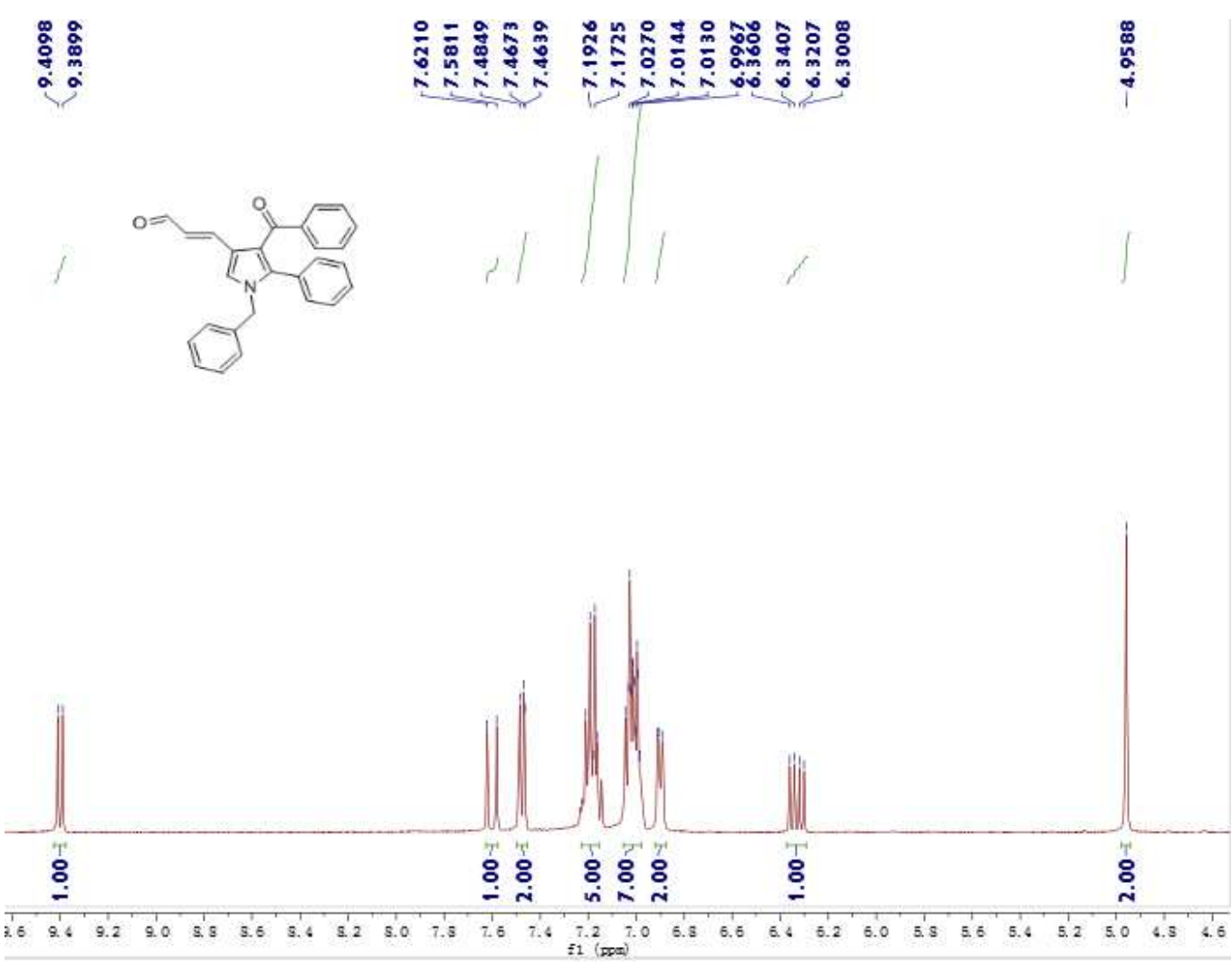

${ }^{1} \mathrm{H}$ NMR spectrum of $\mathbf{8 p}$
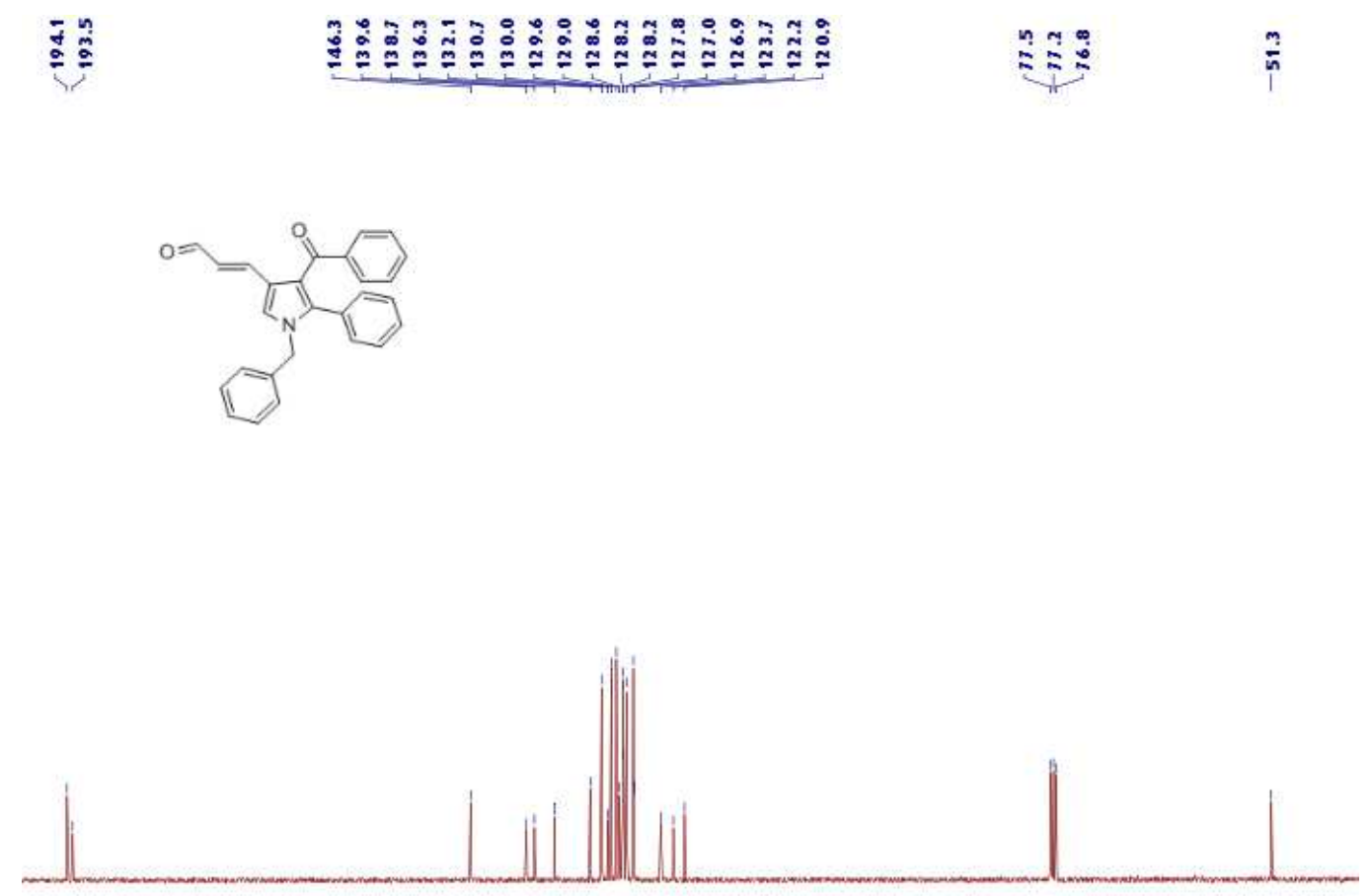

${ }^{13} \mathrm{C}$ NMR spectrum of $\mathbf{8 p}$ 


\section{CIF information of $7 \mathbf{c}$}
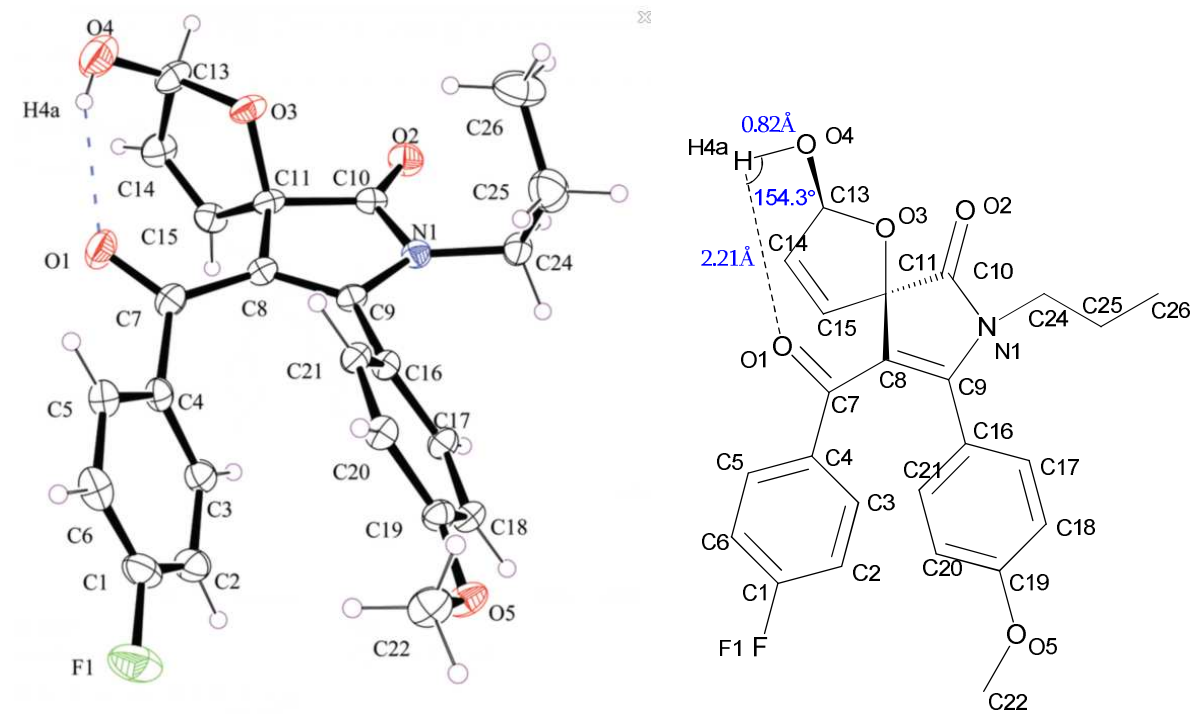

X-ray structure of $7 \mathrm{c}$ with $30 \%$ ellipsoid probability.

\begin{tabular}{|l|l|}
\hline Identification code & Sad \\
Empirical formula & $\mathrm{C} 24 \mathrm{H} 21 \mathrm{~F} \mathrm{~N} \mathrm{O5}$ \\
Formula weight & 422.42 \\
Temperature & $571(2) \mathrm{K}$ \\
Wavelength & $0.71073 \AA$ \\
Crystal system, space group & Triclinic, P21/n \\
Unit cell dimensions & $\mathrm{a}=10.5930(3) \AA \quad$ alpha $=90 \mathrm{deg}$. \\
& $\mathrm{b}=11.1116(3) \AA \quad$ beta $=95.862(3) \mathrm{deg}$. \\
& $\mathrm{c}=17.5737(5) \AA \quad$ gamma $=90 \mathrm{deg}$. \\
Volume & $2057.70(10) \AA^{3}$ \\
Z, Calculated density & $4,1.364 \mathrm{Mg} / \mathrm{m}^{3}$ \\
Absorption coefficient & $0.102 \mathrm{~mm}^{-1}$ \\
F(000) & 884 \\
Crystal size & $0.25 \mathrm{x} 0.20 \mathrm{x} 0.18 \mathrm{~mm}$ \\
Theta range for data collection & 2.15 to $24.25 \mathrm{deg}$. \\
Limiting indices & $-12<=\mathrm{h}<=12,-12<=\mathrm{k}<=12,-20<=1<=20$ \\
Reflections collected / unique & $32467 / 3287[\mathrm{R}(\mathrm{int})=0.0545]$ \\
Completeness to theta $=24.25$ & $98.8 \%$ \\
Max. and min. transmission & 0.9819 and 0.9750 \\
Refinement method & Full-matrix least-squares on $\mathrm{F}^{2}$ \\
Data / restraints / parameters & $3287 / 0 / 281$ \\
Goodness-of-fit on F ${ }^{2}$ & 1.085 \\
Final R indices [I $>2$ sigma(I)] & $\mathrm{R} 1=0.0693, \mathrm{wR} 2=0.1822$ \\
$\mathrm{R}$ indices (all data) & $\mathrm{R} 1=0.0728, \mathrm{wR} 2=0.1849$ \\
Extinction coefficient & $0.021(4)$ \\
Largest diff. peak and hole & 1.429 and $-0.353 \mathrm{e} . \AA^{-3}$ \\
\hline 35 &
\end{tabular}



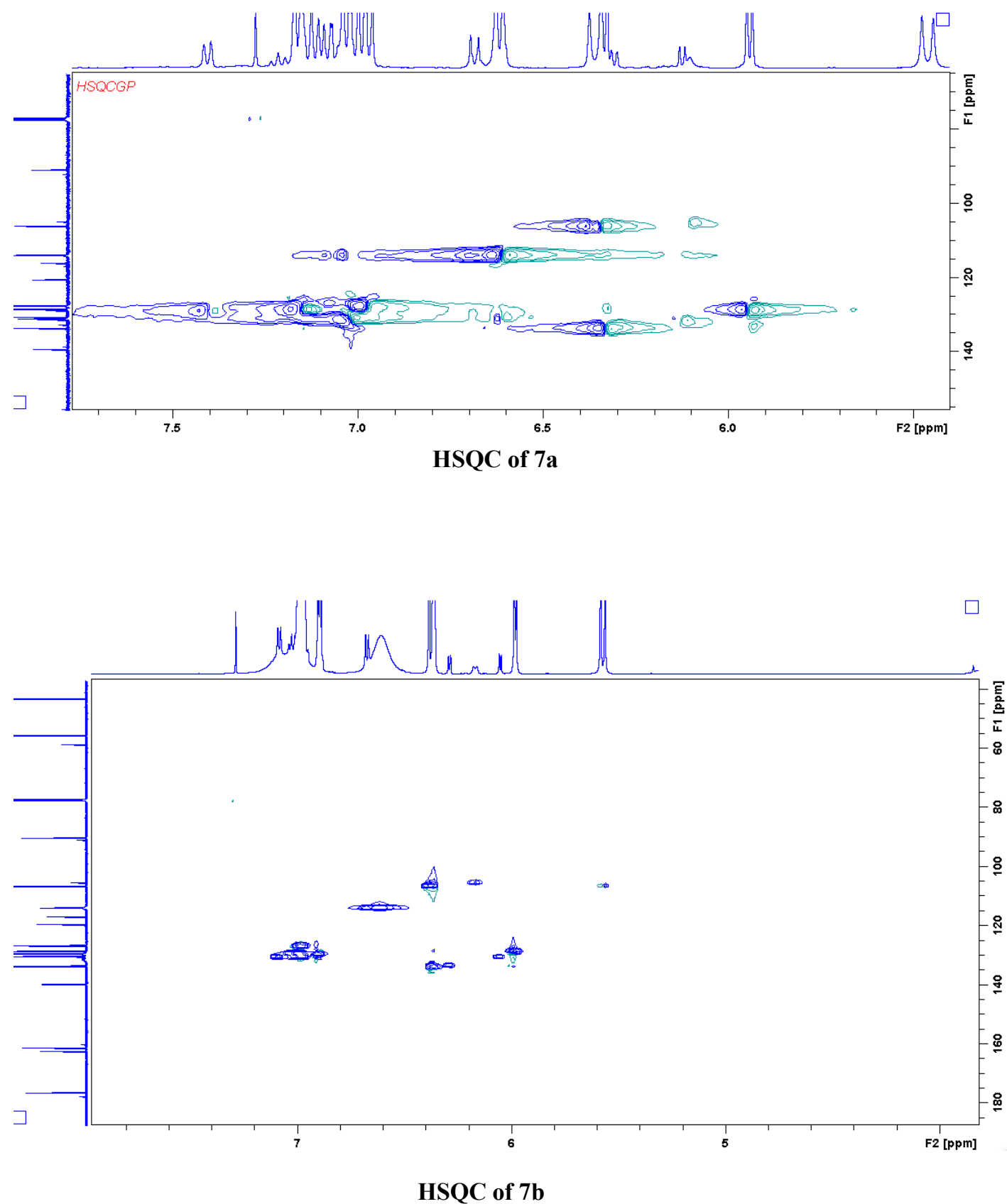

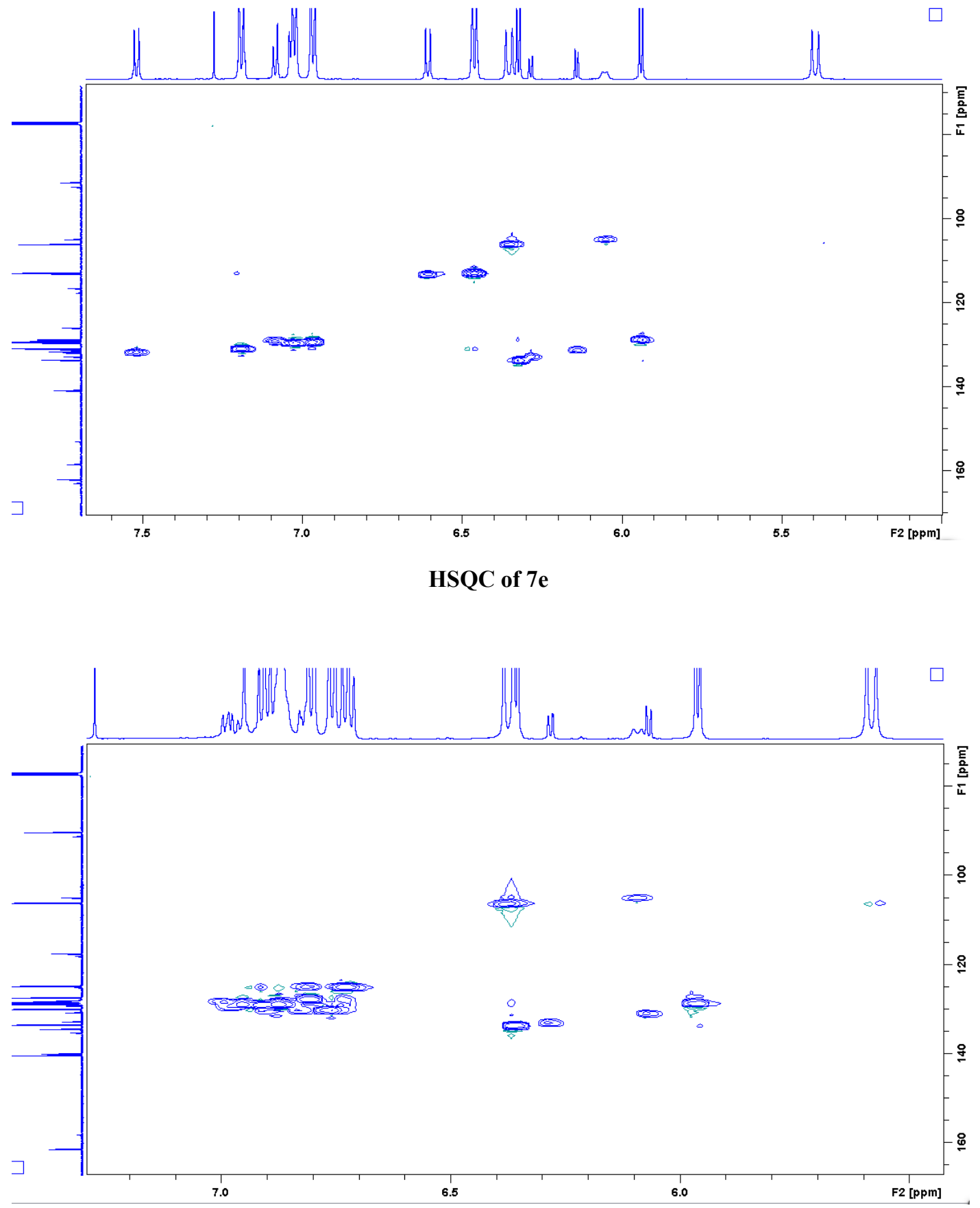

HSQC of 7r 